July 27,1992

\title{
Effect of Vacuum Chamber Eddy Current and Compensation by Digital Feedback
}

\author{
Y. Chung
}

Advanced Photon Source Argonne National Laboratory Argonne, IL 60439

\begin{abstract}
Measurement of the effect of the eddy current induced in the APS storage ring vacuum chamber by the storage ring sextupole magnet and its compensation using digital feedback with proportional, integral, and derivative (PID) control algorithm are presented. The magnetic field in the vacuum chamber shows strong quadrupole and sextupole components varying with frequency, in addition to significant attenuation and phase shift. Large changes in the magnet resistance and inductance were also observed. Development of a theory of digital feedback to obtain system responses and the conditions for optimal control will be described, in conjuction with design of a digital filter to compensate for the eddy current effect.
\end{abstract}




\section{DISCLAIMER}

This report was prepared as an account of work sponsored by an agency of the United States Government. Neither the United States Government nor any agency thereof, nor any of their employees, make any warranty, express or implied, or assumes any legal liability or responsibility for the accuracy, completeness, or usefulness of any information, apparatus, product, or process disclosed, or represents that its use would not infringe privately owned rights. Reference herein to any specific commercial product, process, or service by trade name, trademark, manufacturer, or otherwise does not necessarily constitute or imply its endorsement, recommendation, or favoring by the United States Government or any agency thereof. The views and opinions of authors expressed herein do not necessarily state or reflect those of the United States Government or any agency thereof. 


\section{DISCLAIMER}

Portions of this document may be illegible in electronic image products. Images are produced from the best available original document. 


\section{Introduction}

In the APS storage ring, an extensive beam position correction system will be implemented comprising many corrector magnets (318 total) and BPMs monitoring the positions of the positron and photon beams. The $\mathrm{AC}$ corrector magnets, which will correct beam motion of up to $100 \mu \mathrm{rad}$ at $25 \mathrm{~Hz}$, induce eddy current in the relatively thick (1/2") aluminum vacuum chamber of the storage ring. The attenuation and phase shift of the magnet field due to this eddy current was measured and compensated for in previous works ${ }^{1-3}$ using analog filters and a dipole magnet used for the Electron Cooling Ring Experiment at Fermilab. ${ }^{4}$ In order to eliminate the problems characteristic of analog circuits, e.g., drift, offset, and sensitivity to temperature change, we will use in this work digital signal processing (DSP) and digital closed loop feedback to control the magnetic field in the vacuum chamber.

A prototype of the storage ring sextupole magnet was used in this work, which has geometry similar to that of the six-pole horizontal/vertical corrector magnet. The effect of the eddy current in the 0.025 "-thick magnet laminations was measured and found to be negligibly small in a previous work. 5

This note will be largely divided into two parts. The first part will describe measurement of the effect of the vacuum chamber eddy current on the horizontal and vertical magnetic fields as functions of frequency and position. Measurement of frequency dependence of the magnet impedance will also be presented. In the second part, we will develop a theory of digital closed loop feedback using analytical methods and present measurement results on the vacuum chamber eddy current effect and its compensation using digital signal processing (DSP) 6,7

\section{Measurement Setup}

Figure 2.1 shows the mechanical and electrical setup for the measurements described in this note. The magnet shown in Fig. 2.1(a) is the storage ring $H / V$ corrector magnet, which has geometry similar to that of the sextupole magnet used in this work. The magnet has main coil windings on all 6 poles and correction coil windings on the 4 side poles. Only the main coil windings were used for this work. The magnet has the effective length of $28.7 \mathrm{~cm},{ }^{8}$ and the vacuum chamber was $4^{\prime}(122 \mathrm{~cm})$ long. A portion of the vacuum chamber was cut away from the positron beam chamber section to fit it in the magnet bore and to reduce eddy current effect. 
(a)

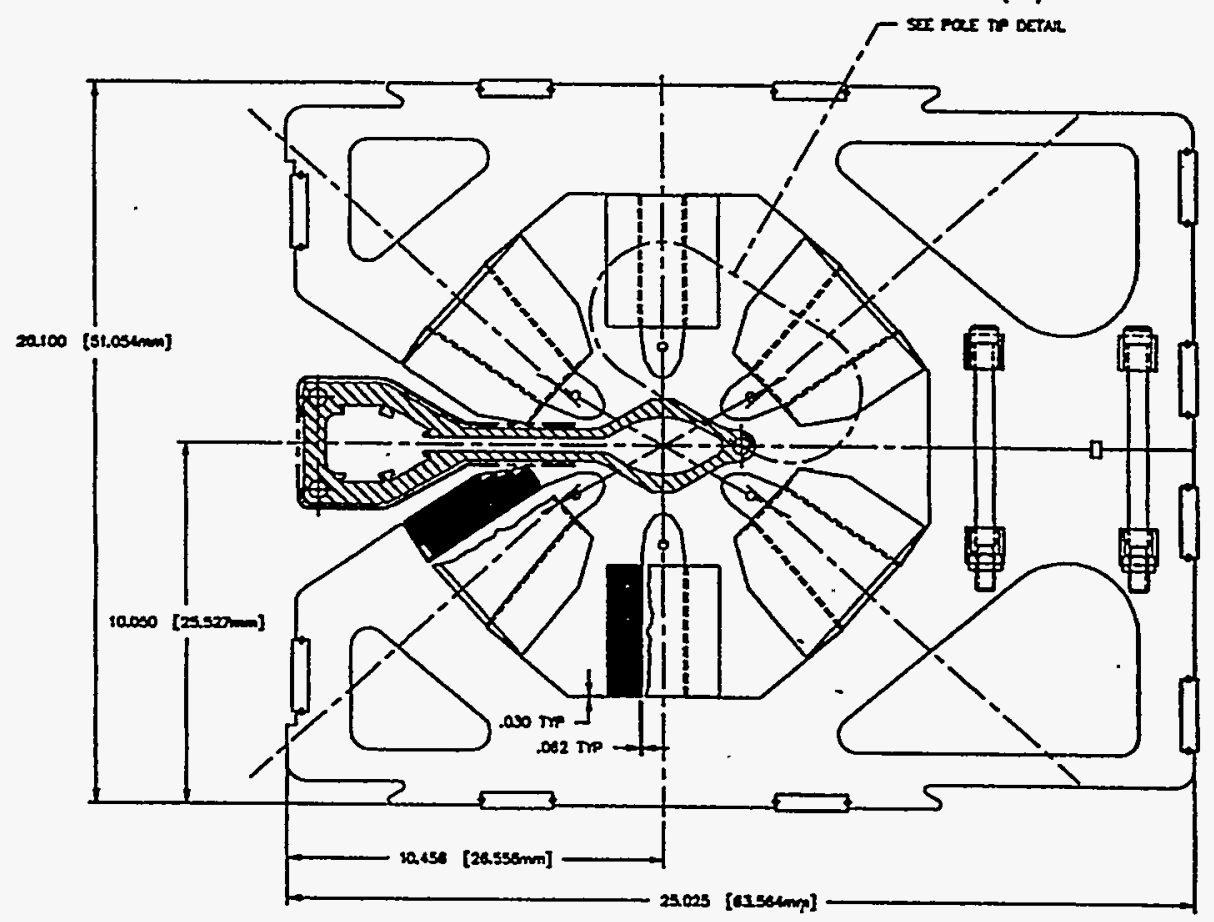

(b)

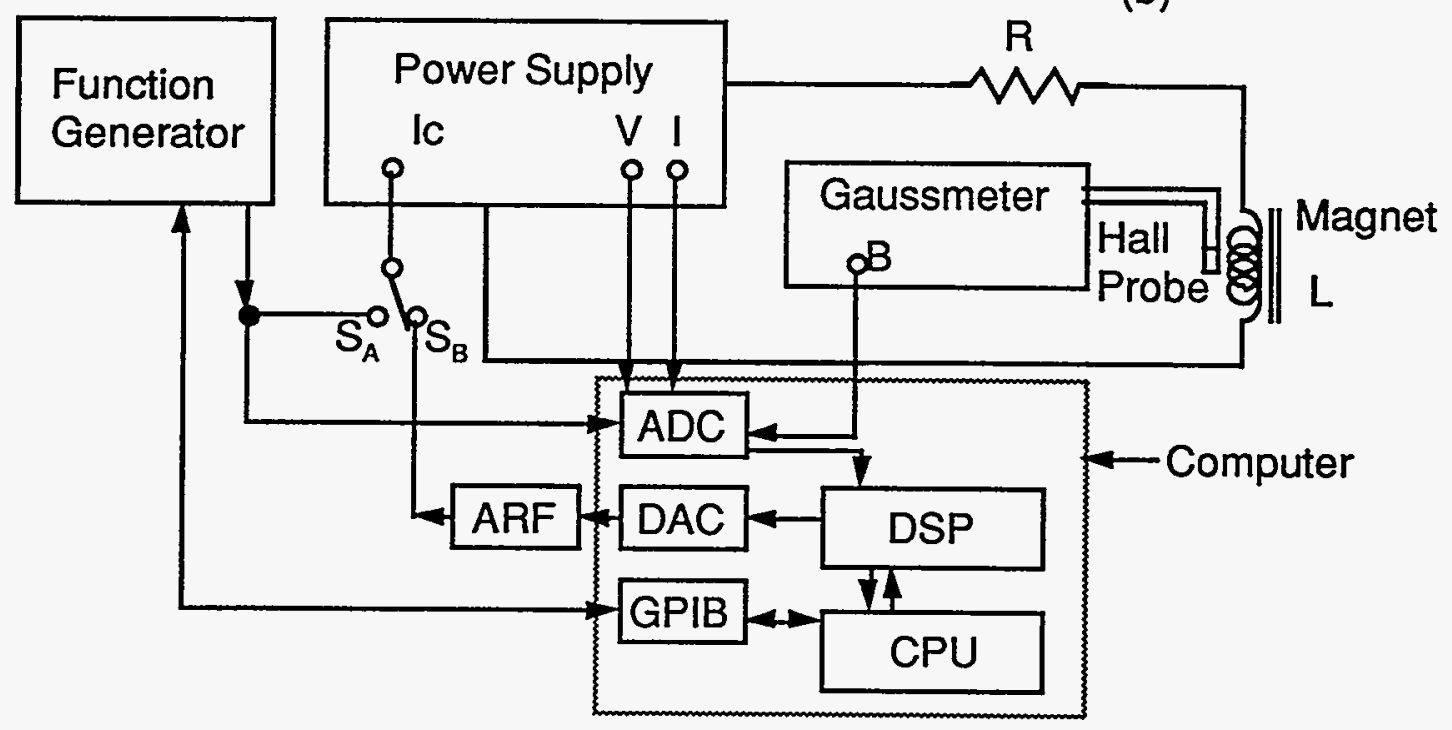

Fig. 2.1: (a) Vacuum chamber cross section in the storage ring $\mathrm{H} / \mathrm{V}$ corrector magnet, similar to the sextupole magnet used in this work. (b) Schematic diagram of measurement setup for the eddy current effect on the magnet field. The voltage (V) and the current (I) signals were provided by the power supply and the magnet field (B) was measured by a gaussmeter with a Hall probe. The ADC and DAC are on the ATMIO-16 board. ARF is an analog reconstruction filter with $200 \mathrm{~Hz}$ bandwidth. 
To simulate the control signal and the noise, e.g., ground vibration and magnet current fluctuation, a function generator (HP Model 3245A) was used. The magnet field was measured using the series 9900 menu-driven multi-channel gaussmeter manufactured by F.W. Bell. The full-scale analog output signal level is $\pm 3 \mathrm{~V}$.

The power supply was a Kepco bipolar operational power supply/amplifier, model No. BOP $20-20 \mathrm{M}$, with voltage range of $\pm 20 \mathrm{~V}$, maximum current of $20 \mathrm{~A}$, and bandwidth of $10 \mathrm{kHz}$ ( $-3 \mathrm{~dB}$ attenuation). The current-controlled mode was used for this work. For open loop measurements the current control signal port $\left(I_{C}\right)$ was connected to the function generator output $\left(\mathrm{S}_{\mathrm{A}}\right)$, and for closed loop measurements it was connected to the analog reconstruction filter $\left(A R F, S_{B}\right)$. Analog voltage and current monitoring signals were provided through an interface card, which were digitized and analyzed by a computer. The full-scale signals are $\pm 10 \mathrm{~V}$ for both the voltage and the current.

The data acquisition and analysis was done by a computer with a 486 processor (CPU), equipped with an ATMIO-16 multifunction I/O board and a GPIB board to interface the function generator. Both of these were manufactured by National Instruments. The ATMIO-16 board, a multichannel ADC/DAC, has 16 input analog-todigital converter (ADC) channels and two output digital-to-analog converter (DAC) channels. Configured for differential input, as in our setup, the maximum number of input channels is 8 . The analog input signal range for the ATMIO- 16 board is $\pm 10 \mathrm{~V}$ for all channels. With the digital resolution of 12 bits, the conversion formula is

$$
\mathrm{V}(\text { in analog })=\frac{10}{2,048} \mathrm{~V} \text { (in digital). }
$$

This gives a resolution of approximately $5 \mathrm{mV}$.

Given a nominal frequency supplied by the user, the actual frequency is first found by counting the integer number of periods and the time elapsed as measured using the clock on the ATMIO board. Using this frequency $f$, the data is fit to the function

$$
\mathrm{V}=\mathrm{V}_{0} \cos (2 \pi \mathrm{ft}+\phi)
$$

using linear least squares method, ${ }^{9}$ which gives the amplitude $V_{0}$ and the phase $\phi$. This procedure is done for the voltage, current, and magnet field, and the amplitudes and phases are compared to obtain the resistance and inductance of the magnet and the attenuation and phase shift of the field due to the eddy current.

The analog-to-digital conversion was done at the maximum rate of 100 ksamples/sec, which introduces a timing error of $10 \mu \mathrm{sec}$ between two adjacent channels. With sinusoidal signal of frequency $\mathrm{f}$, the phase measurement error per $\mathrm{Hz}$ per channel is 


$$
\frac{\Delta \phi \text { (degrees) }}{\mathrm{f}(\mathrm{Hz})}=3.6 \times 10^{-3} .
$$

The result of measurement on $\Delta \phi / f$ at the frequencies of 10,100 , and $200 \mathrm{~Hz}$ is shown in Table 2.1. This phase error was compensated for in the subsequent measurements.

Table 2.1: Measurement results of the phase delay between channels 1,2, and 3 of the ATMIO-16 board.

\begin{tabular}{|c|c|c|}
\hline Frequency $(\mathrm{Hz})$ & $\begin{array}{c}\Delta \phi / \mathrm{f}(\text { degrees } / \mathrm{Hz}) \\
\text { between Channels 1\&2 }\end{array}$ & $\begin{array}{c}\Delta \phi / \mathrm{f}(\text { degrees } / \mathrm{Hz}) \\
\text { between Channels 1\&3 }\end{array}$ \\
\hline 10 & $-3.50 \mathrm{E}-03 \pm 1.61 \mathrm{E}-04$ & $-7.05 \mathrm{E}-03 \pm 2.38 \mathrm{E}-04$ \\
100 & $-3.59 \mathrm{E}-03 \pm 1.59 \mathrm{E}-05$ & $-7.19 \mathrm{E}-03 \pm 1.86 \mathrm{E}-05$ \\
200 & $-3.60 \mathrm{E}-03 \pm 4.57 \mathrm{E}-06$ & $-7.21 \mathrm{E}-03 \pm 7.15 \mathrm{E}-06$ \\
\hline
\end{tabular}

\section{Measurement of Magnet Impedance}

Let us write, assuming harmonic time dependence $\mathrm{e}^{-\mathrm{i} \omega \mathrm{t}}$,

$$
\frac{\mathrm{V}}{\mathrm{I}}=\left|\frac{\mathrm{V}}{\mathrm{I}}\right| \mathrm{e}^{\mathrm{i} \phi}=\mathrm{R}-\mathrm{i} \omega \mathrm{L},
$$

which gives

$$
\mathrm{R}=\left|\frac{\mathrm{V}}{\mathrm{I}}\right| \cos \phi \quad \text { and } \mathrm{L}=-\frac{1}{\omega}\left|\frac{\mathrm{V}}{\mathrm{I}}\right| \sin \phi
$$

$\phi$ is the phase shift between the current and the voltage. For an inductive load, such as a magnet, $\phi$ is negative. The current $I$ and the field $B$ are related by

$$
\mathrm{B}=\mathrm{C}|\mathrm{I}| \mathrm{ae} \mathrm{e}^{-\mathrm{i} \varphi,}
$$

where $\mathrm{C}$ is a factor that normalizes a to 1 at $\mathrm{DC}$, and a and $\varphi$ are the attenuation factor and the phase shift primarily due to the vacuum chamber eddy current. To avoid the offset calibration error in the output monitoring signals provided by the power supply, an AC signal of very low frequency, say $0.1 \mathrm{~Hz}$, was applied instead of a DC signal to measure 
(a)

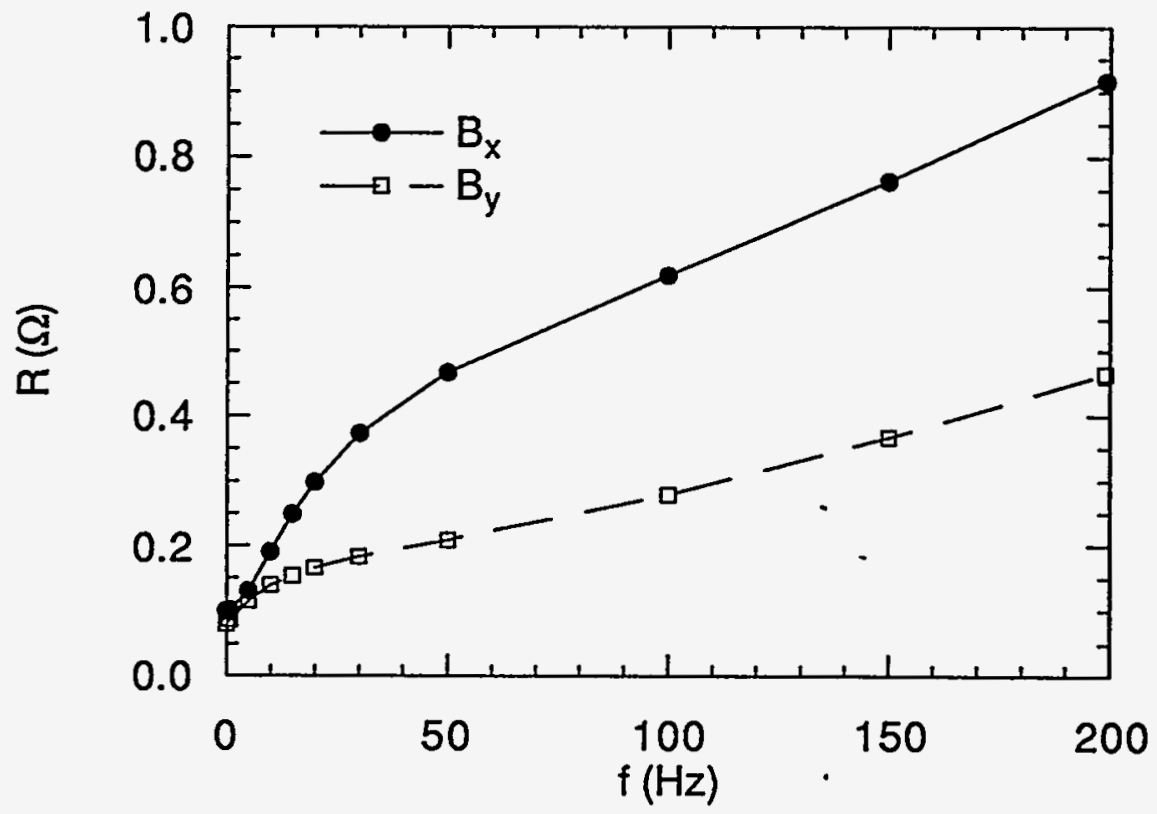

(b)

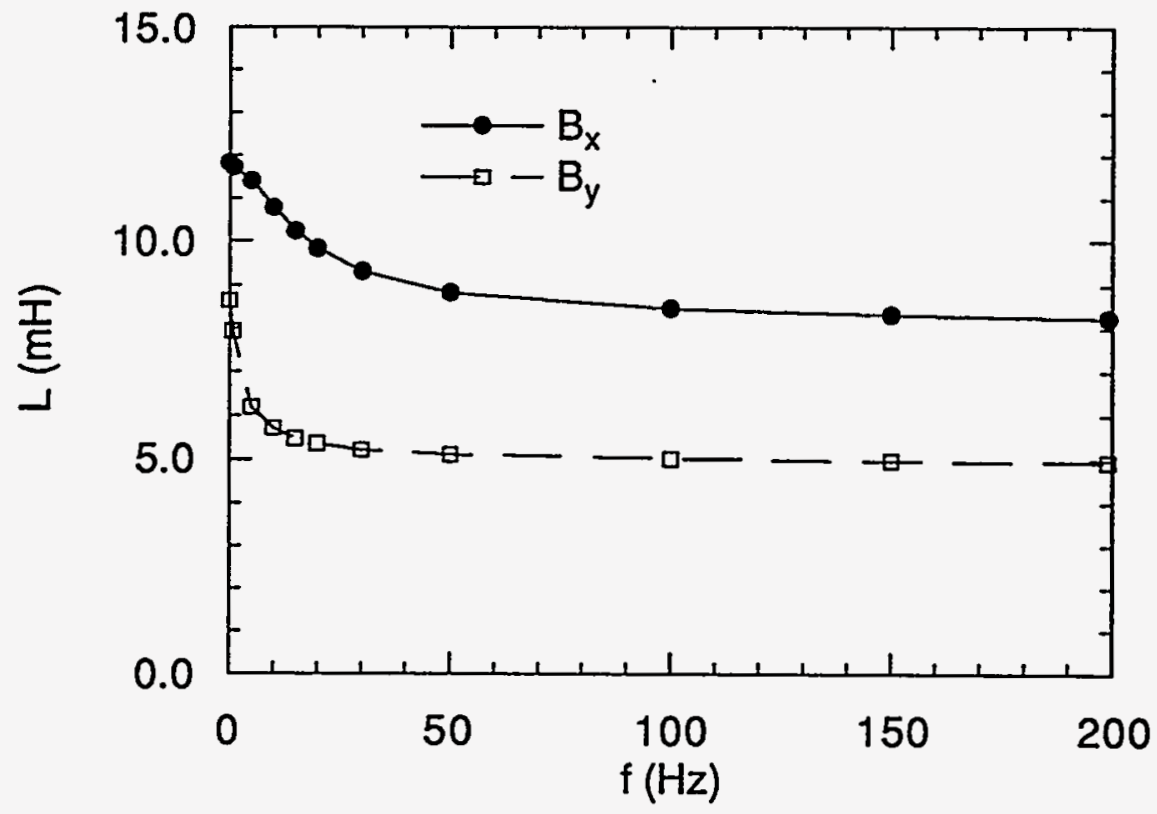

Fig. 3.1: Change of magnet impedance due to the vacuum chamber eddy current as a function of frequency: (a) resistance $\mathrm{R}$ in units of $\Omega$ and (b) inductance $\mathrm{L}$ in units of $\mathrm{mH}$. 
the amplitude ratio. The current was maintained at $\approx 1 \mathrm{~A}$, which produced a magnetic field of $\approx 12 \mathrm{G}$ at DC, and the scale on the gaussmeter was set to $30 \mathrm{G}$.

Figure 3.1(a) shows the results of measurements on the resistance of the magnet connected as vertical and horizontal correctors and Fig. 3.1(b) shows the results of measurements on the inductance. The large change in the magnet impedance with increasing frequency is mainly attributable to the eddy current in the vacuum chamber. The effect of the eddy current in $0.025^{\prime \prime}$-thick magnet laminations is negligible. ${ }^{5}$

\section{Measurement of Field Attenuation and Phase Shift}

Attenuation and phase shift of the magnetic field relative to the driving magnet current were measured in a manner similar to measurement of the magnet impedance as described in the previous section, and the amplitude ratio and phase difference between the field $B$ and the magnet current $I$ were measured.

In Fig. 4.1(a) and 4.1(b) are shown the attenuation and phase shift of the field relative to the magnet current as functions of frequency at the center of the vacuum chamber $(x=0)$. The vertical field shows stronger attenuation and phase shift with frequency than the horizontal field, though the horizontal field appears to catch up in the high frequency region. Qualitatively, this is due to the geometry of the magnet poles and the vacuum chamber, which is vertically a little thinner but has a much larger surface cutting the magnetic flux than horizontally. This large aspect ratio and proximity of the magnet poles to the surface may create a more unfavorable condition for the vertical than the horizontal field.

Figures 4.2(a) and 4.2(b) show behavior of the magnetic field in the vacuum chamber as a function of the frequency and the horizontal distance $x$ from the center. The antechamber side of the storage ring vacuum chamber is the positive direction. The magnetic field was measured at the positions $x=-10,-5,0,5$, and $10 \mathrm{~mm}$ relative to the center of the vacuum chamber and at various frequencies. The data measured at the frequencies $\mathrm{f}=0.1,5,20,50,100$, and $200 \mathrm{~Hz}$ are shown. Both the amplitude and phase show strong dependence on frequency and position. When the frequency is low (below 20 $\mathrm{Hz}$ ), the quadrupole component of the magnetic field increases with frequency. Assuming harmonic time dependence $e^{-i \omega t}$, we write the vertical component of the magnetic field $B_{y}$ as

$$
B_{y}(x, \omega)=B_{y 0}(\omega)\left[1+b_{1}(\omega) x+b_{2}(\omega) x^{2}\right] . \quad(y=0)
$$


(a)

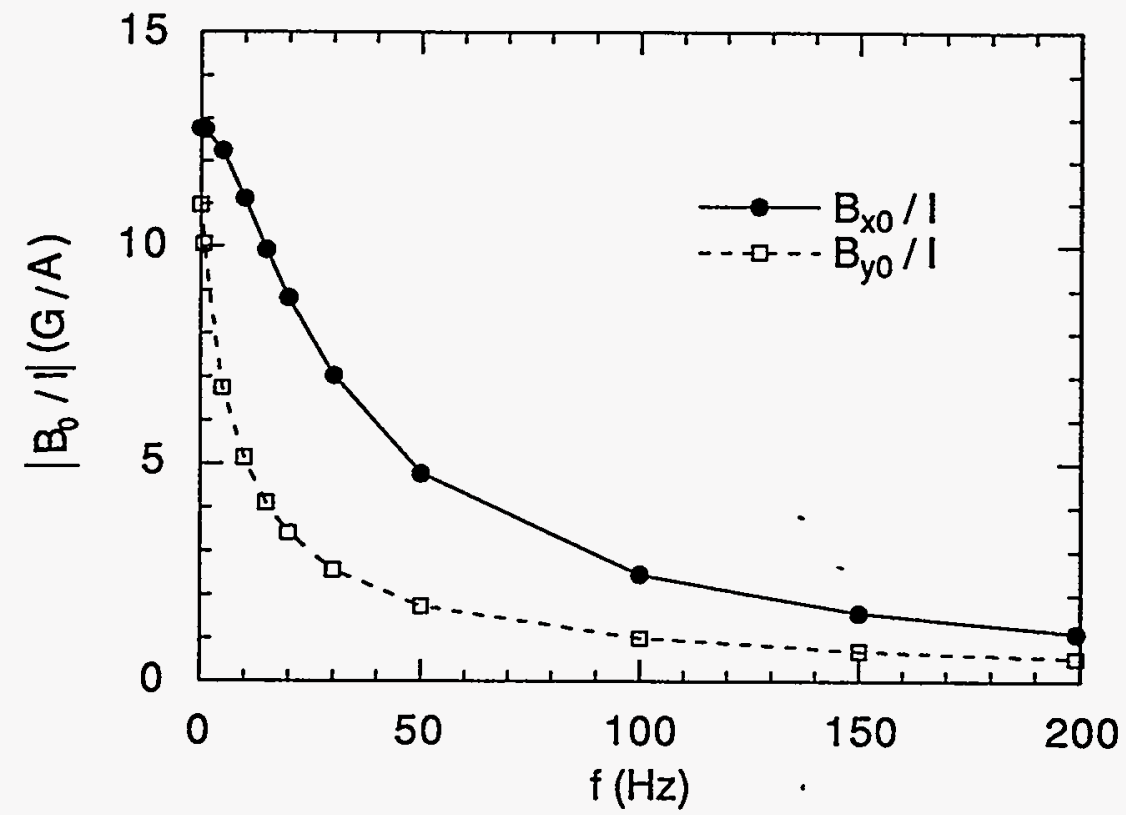

(b)

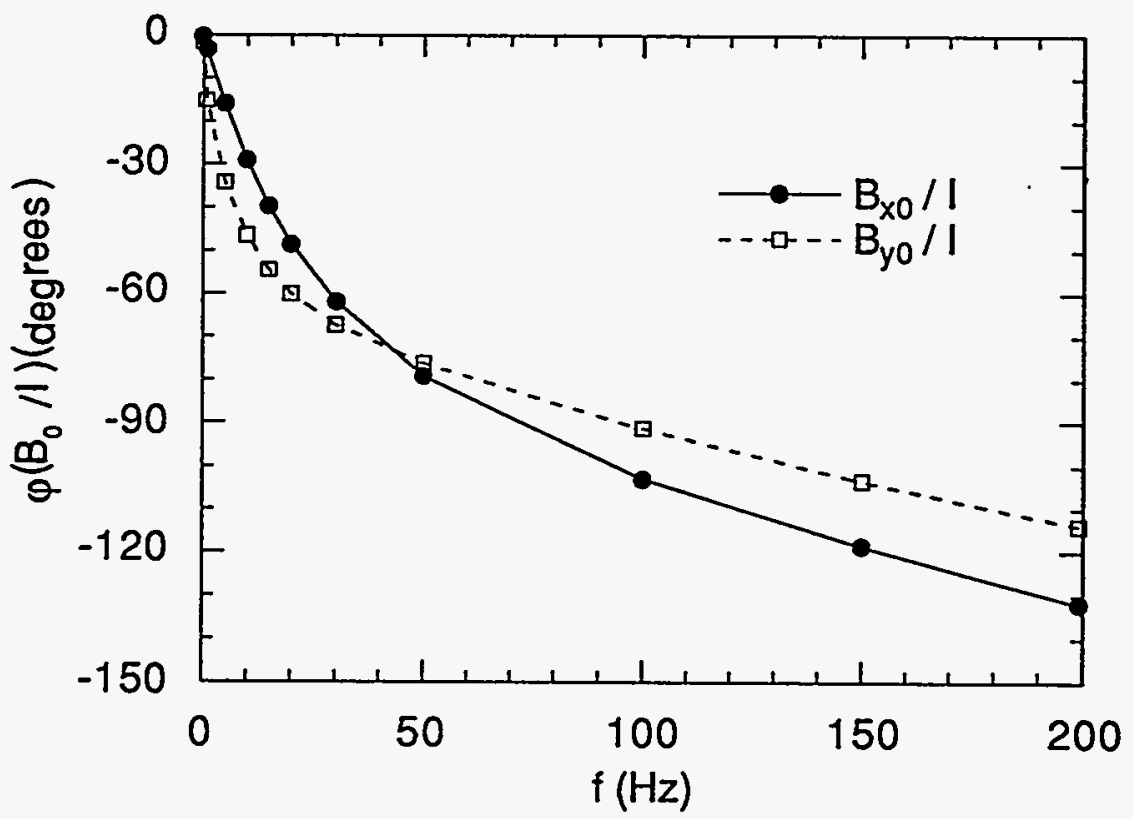

Fig. 4.1: (a) Attenuation of the field efficiency $\mid B_{x, y} / I l$ and (b) phase shift $\varphi$ between the field and the current as functions of frequency at the center of the vacuum chamber $(x=0)$. 
(a)

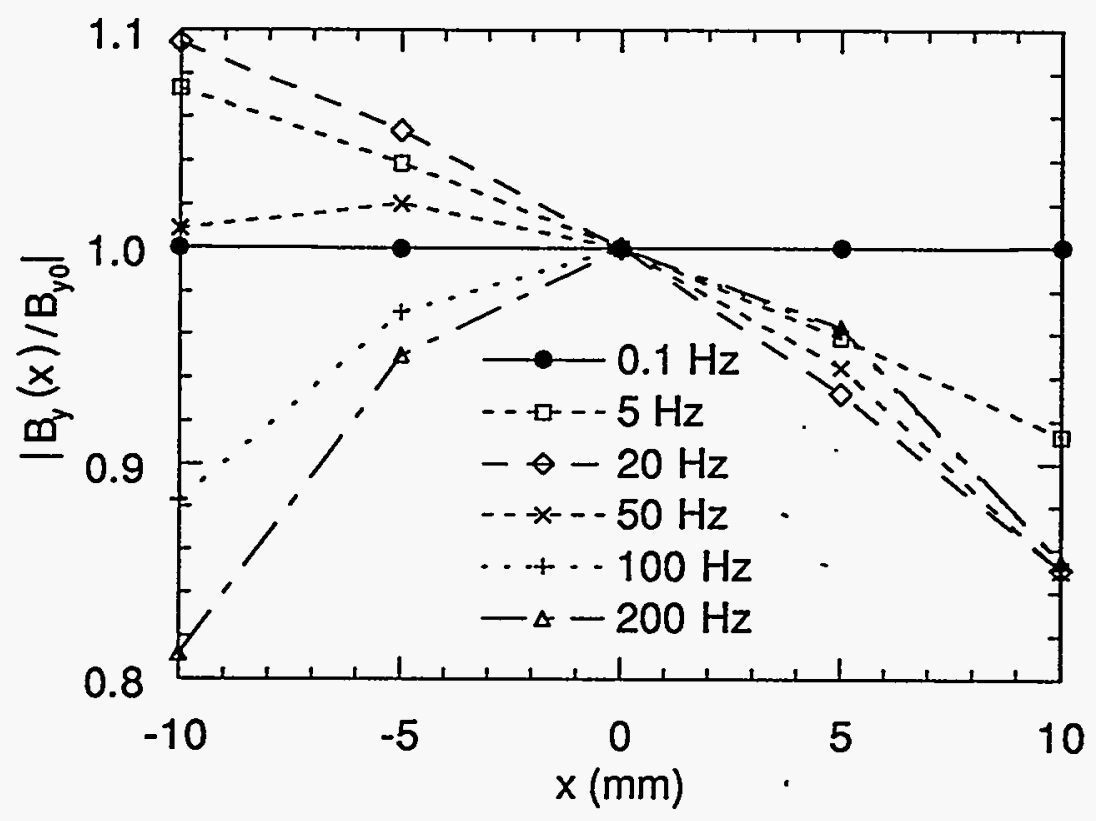

(b)

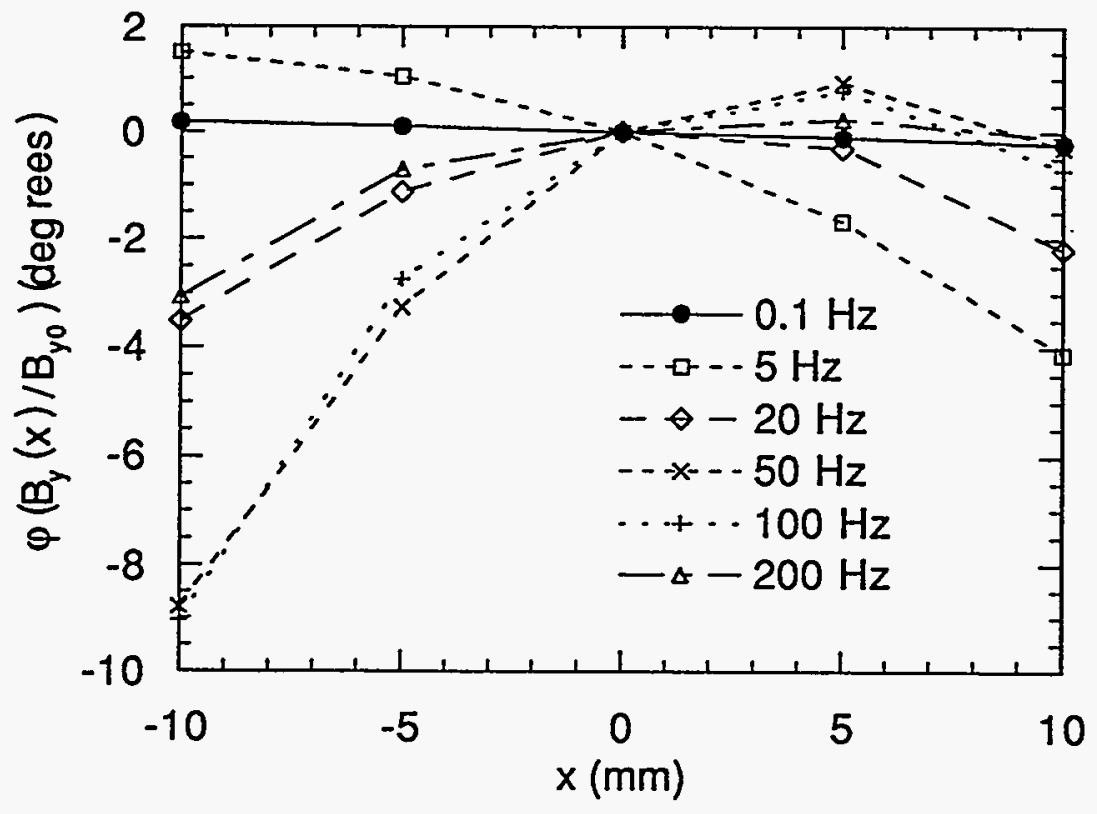

Fig. 4.2: Dependence of the magnetic field in the vacuum chamber on the position and the frequency. $\mathrm{x}$ is the horizontal distance from the center where the field was measured. The antechamber side is the positive direction. (a) Amplitude attenuation and (b) phase delay relative to the center $(x=0)$. 
$b_{1}$ is the dipole coefficient and $b_{2}$ is the sextupole coefficient. The horizontal field component $\mathrm{B}_{\mathrm{x}}$ can be expanded in a similar form. In this work, the horizontal field was measured only at the center $(x=0, y=0)$ for $B_{x} 0(\omega)$ at several different frequencies. The amplitude and phase of the center fields $\mathrm{B}_{\mathrm{y} 0}$ and $\mathrm{B}_{\mathrm{x} 0}$ show very strong dependence on the frequency of the driving current due to the eddy current in the vacuum chamber.

The coefficients $b_{1}(\omega)$ and $b_{2}(\omega)$ are complex numbers varying with frequency. That is, we can write

$$
b_{1}(\omega)=b_{1 r}(\omega)+i b_{1 i}(\omega) \quad \text { and } \quad b_{2}(\omega)=b_{2 r}(\omega)+i b_{2 i}(\omega)
$$

The values of $b_{1 r}, b_{1 i}, b_{2 r}$, and $b_{2 i}$ are listed in Table 4.1 and are plotted in Fig. 4.2. Below $50 \mathrm{~Hz}$, which is the frequency range of our interest for beam position correction, the quadrupole components dominate, and beyond $100 \mathrm{~Hz}$, the sextupole components dominate. The strong quadrupole coefficient, which increases rapidly in magnitude in the low frequency range $[0,20] \mathrm{Hz}$, is a cause for concern. For local beam position feedback, which employs four corrector magnets to adjust the angle and displacement of the photon source, the corrector magnet field in the vacuum chamber must be very uniform to prevent local bump closure error. The good-field requirement on the corrector magnet field is 10

$$
\frac{\Delta \mathrm{B}}{\mathrm{B}_{0}}<8 \times 10^{-3}, \text { for }|\mathrm{x}| \leq 3.2 \mathrm{~mm} \text {. }
$$

Using $b_{1 r}=-0.12$ and $b_{1 i}=0.017$ at $f=20 \mathrm{~Hz}$, we have

$$
\frac{\Delta \mathrm{B}}{\mathrm{B}_{0}} \approx 0.039 \text { at }|\mathrm{x}|=3.2 \mathrm{~mm}, \mathrm{f}=20 \mathrm{~Hz}
$$

which is about 5 times larger than required by Eq. (4.3).

\section{Theory of Digital Closed Loop Feedback}

In this section, we will develop a theory of digital closed loop feedback using proportional $(\mathrm{P})$ control. We will first start with analysis of the simplest of closed loop feedback systems with only one element, a gain of G, and show that the system is not usable. We will then insert one or more filtering elements in series with the gain in the feedback loop and analyze the system for stability. Particularly, we will derive the condition for stability and for the optimal control of a feedback system in terms of the open loop gain, the open loop bandwidth, and the sampling frequency. 
Table 4.1: Multipole components of the magnetic field in the vacuum chamber.

\begin{tabular}{|r|rrrr|}
\hline $\mathrm{f}(\mathrm{Hz})$ & $\mathrm{b}_{1 \mathrm{r}}\left(\mathrm{cm}^{-1}\right)$ & $\mathrm{b}_{1 \mathrm{i}}\left(\mathrm{cm}^{-1}\right)$ & $\mathrm{b}_{2 \mathrm{r}}\left(\mathrm{cm}^{-2}\right)$ & $\mathrm{b}_{2 \mathrm{i}}\left(\mathrm{cm}^{-2}\right)$ \\
\hline 0.1 & $-5.06 \mathrm{e}-05$ & $-3.62 \mathrm{e}-03$ & $5.62 \mathrm{e}-04$ & $-4.12 \mathrm{e}-04$ \\
1 & $-1.18 \mathrm{e}-02$ & $-3.28 \mathrm{e}-02$ & $-4.84 \mathrm{e}-04$ & $-6.26 \mathrm{e}-03$ \\
5 & $-8.11 \mathrm{e}-02$ & $-4.67 \mathrm{e}-02$ & $-8.70 \mathrm{e}-03$ & $-1.87 \mathrm{e}-02$ \\
10 & $-1.10 \mathrm{e}-01$ & $-2.45 \mathrm{e}-02$ & $-1.48 \mathrm{e}-02$ & $-3.02 \mathrm{e}-02$ \\
15 & $-1.20 \mathrm{e}-01$ & $-2.52 \mathrm{e}-03$ & $-2.15 \mathrm{e}-02$ & $-4.05 \mathrm{e}-02$ \\
20 & $-1.20 \mathrm{e}-01$ & $1.69 \mathrm{e}-02$ & $-2.90 \mathrm{e}-02$ & $-4.94 \mathrm{e}-02$ \\
30 & $-1.11 \mathrm{e}-01$ & $4.72 \mathrm{e}-02$ & $-4.50 \mathrm{e}-02$ & $-6.30 \mathrm{e}-02$ \\
50 & $-7.37 \mathrm{e}-02$ & $7.46 \mathrm{e}-02$ & $-7.69 \mathrm{e}-02$ & $-7.85 \mathrm{e}-02$ \\
100 & $-8.71 \mathrm{e}-03$ & $6.31 \mathrm{e}-02$ & $-1.37 \mathrm{e}-01$ & $-7.58 \mathrm{e}-02$ \\
150 & $1.63 \mathrm{e}-02$ & $3.99 \mathrm{e}-02$ & $-1.59 \mathrm{e}-01$ & $-4.50 \mathrm{e}-02$ \\
200 & $2.03 \mathrm{e}-02$ & $1.98 \mathrm{e}-02$ & $-1.67 \mathrm{e}-01$ & $-2.35 \mathrm{e}-02$ \\
\hline
\end{tabular}

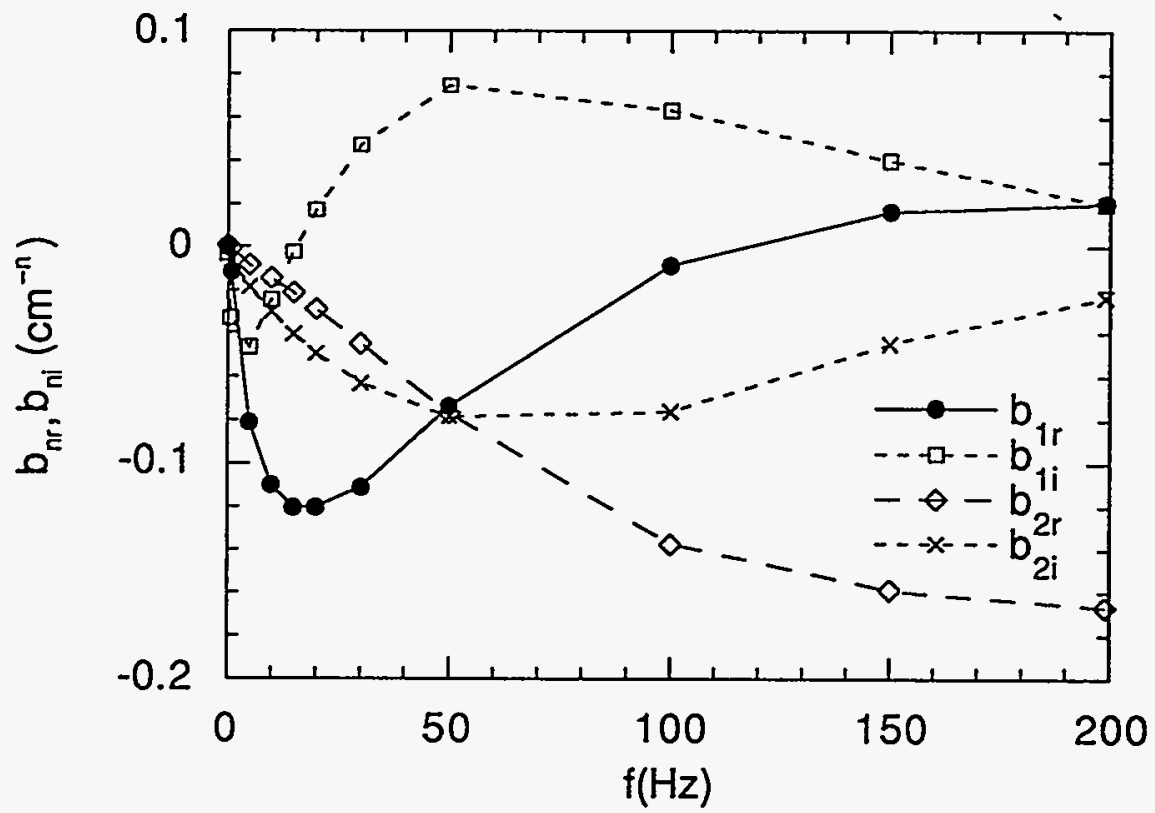

Fig. 4.3: Plotting of the multipole coefficients $b_{1 r}, b_{1 i}, b_{2 r}$, and $b_{2 i}$ as functions of frequency. 


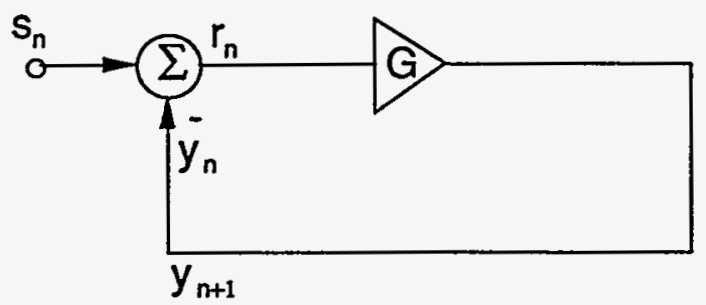

Fig. 5.1: A simple digital closed loop feedback system with open loop gain $G>0$.

In Fig. 5.1 is shown a simple digital feedback system with positive open loop gain G. The discreet input sequence $\left\{s_{n}\right\}$ and the output sequence $\left\{y_{n}\right\}$ are related through

$$
y_{n+1}=G\left(s_{n}-y_{n}\right) . \quad(G>0)
$$

Let us for simplicity take an example of an input step impulse $\left\{\mathrm{s}_{\mathrm{n}}\right\}$ given by

$$
\mathrm{s}_{\mathrm{n}}= \begin{cases}0, & \mathrm{n}<0 \\ 1 . & \mathrm{n} \geq 0 .\end{cases}
$$

The initial condition for the output sequence $\left\{y_{n}\right\}$ is $y_{n}=0$ for $n \leq 0$. Then the difference equation in Eq. (5.1) is solvable and the solution is given by

$$
y_{n}=\frac{G}{1+G}\left(1-(-G)^{n}\right) . \quad(n \geq 0)
$$

We immediately see that when $G$ is greater than 1 , the feedback system is unstable. When $\mathrm{G}$ is less than 1, the system is stable, but the transient behavior at the onset of the step impulse is strongly oscillatory. Writing down a few terms after $n=0$, we have

$$
y_{0}=0, \quad y_{1}=G, \quad y_{2}=G(1-G), \quad y_{3}=G\left(1-G+G^{2}\right),
$$

and it finally settles to

$$
\lim _{n \rightarrow \infty} y_{n}=\frac{G}{1+G} . \quad(G<1)
$$

Therefore, even when $G$ is less than one, the large overshoot and the oscillatory behavior of the system renders it unusable as a control system. Moreover, since our goal is rejection of noise perturbing the beam position, the open loop gain $G$ needs to be larger than 1 . This necessitates insertion of a low-pass filter in series with the gain in order to suppress the oscillation and stabilize the system. In the following sections, we will investigate the 
stability criteria of a feedback system with one or more filtering elements in the feedback loop.

\subsection{Digital Feedback with One Filtering Element}

To determine the relation between the sampling frequency and the bandwidth for the optimal feedback control, let us consider a simple feedback system with proportional control and a constant loop gain $\mathrm{G}$ as shown in Fig. 5.2.

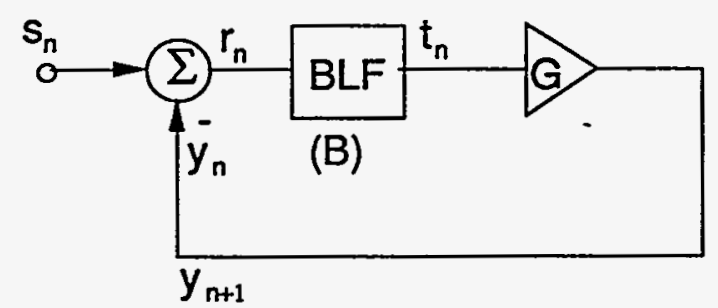

Fig. 5.2: A simple P-control closed loop feedback system.

The band-limiting filter (BLF) is a single-pole digital low-pass filter with bandwidth of $f_{b}$. The sampling frequency of the system is denoted by $F_{s}$. We will use the filter parameter $c$ given by 5

$$
c=\cot \left(\frac{\pi f_{b}}{F_{s}}\right)
$$

The signal symbols $s_{n}, y_{n}, r_{n}$, and $t_{n}$ are related to each other by

$$
r_{n}=s_{n}-y_{n}, \quad t_{n}=\frac{1}{1+c}\left[r_{n}+r_{n-1}-(1-c) t_{n-1}\right], \text { and } y_{n+1}=G t_{n} \text {. }
$$

Combining the three equations in Eq. (5.7), we obtain

$$
(1+c) y_{n+1}+(1-c+G) y_{n}+G y_{n-1}=G\left(s_{n}+s_{n-1}\right) .
$$

This is a difference equation for the discreet sequences $\left\{s_{n}\right\}$ and $\left\{y_{n}\right\}$. The output $\left\{y_{n}\right\}$ should follow the given control signal $\left\{s_{n}\right\}$ as closely as possible without divergence. Given the initial conditions $y_{0}$ and $y_{1}$, the output of the system is uniquely defined in terms of the input. 
The stability analysis of the system for general input sequence $\left\{s_{n}\right\}$ can be done using the Z-transform. ${ }^{6,7}$ However, to get more insight into the temporal behavior of the system, we will use Fourier analysis after rewriting Eq. (5.8) into a differential equation, assuming that the output $\left\{y_{n}\right\}$ is well-behaved; that is,

$$
\left|y_{n+1}-y_{n}\right| \ll \max \left|y_{n}\right| \text {. }
$$

Using

$$
s=\frac{1}{2}\left(s_{n}+s_{n-1}\right), \quad y=y_{n}, \quad y^{\prime} \approx \frac{1}{2}\left(y_{n+1}-y_{n-1}\right), \quad \text { and } \quad y^{\prime \prime} \approx y_{n+1}-2 y_{n}+y_{n-1},
$$

where the prime $\left({ }^{\prime}\right)$ is a time derivative operator defined as

$$
, \equiv \frac{1}{F_{s}} \frac{d}{d t},
$$

we have

$$
(1+c+G) y^{\prime \prime}+2(1+c-G) y^{\prime}+4(1+G) y=4 G s .
$$

Equation (5.12) is an inhomogeneous second-order differential equation in y. Assuming harmonic time dependence $\mathrm{e}^{-\mathrm{i} \omega \mathrm{t}}$, the Fourier transform of Eq. (5.12) gives,

$$
\tilde{y}=\tilde{s} \frac{G}{1+G}\left(\frac{\gamma_{1}}{\gamma_{1}-i \omega}\right)\left(\frac{\gamma_{2}}{\gamma_{2}-i \omega}\right),
$$

where eigenvalues $\gamma_{1}$ and $\gamma_{2}$ are solutions of the quadratic secular equation

$$
(1+c+G) \gamma^{2}-2(1+c-G) \gamma F_{s}+4(1+G) F_{s}^{2}=0 .
$$

$\tilde{y}$ and $\widetilde{s}$ are Fourier transforms of $y$ and s, respectively. Equation (5.13) shows that the closed loop feedback system with a single-pole low pass filter acts like a two-pole filter. The open loop gain $\mathrm{G}$ and the filter parameter $\mathrm{c}$ determine the stability of the system through $\gamma_{1}$ and $\gamma_{2}$ as follows:

$$
\begin{cases}\operatorname{Re}\left(\gamma_{1}, \gamma_{2}\right)>0, \operatorname{Im}\left(\gamma_{1}, \gamma_{2}\right)=0 & \rightarrow \text { overdamped, stable } \\ \gamma_{1}=\gamma_{2}>0 & \rightarrow \text { critically damped, stable } \\ \operatorname{Re}\left(\gamma_{1}, \gamma_{2}\right)>0, \operatorname{Im}\left(\gamma_{1}, \gamma_{2}\right) \neq 0 & \rightarrow \text { underdamped, stable but oscillatory } \\ \operatorname{Re}\left(\gamma_{1}\right)=\operatorname{Re}\left(\gamma_{2}\right)=0 & \rightarrow \text { undamped } \\ \operatorname{Re}\left(\gamma_{1}\right)<0 \text { or } \operatorname{Re}\left(\gamma_{2}\right)<0 & \rightarrow \text { unstable }\end{cases}
$$


The feedback system is stable only when both $\gamma_{1}$ and $\gamma_{2}$ have positive real parts. From Eq. (5.14), this is satisfied if $1+c-G>0$. Expanding the solution of Eq. (5.14) to the first order of $f_{b}$, assuming $c$ is large $\left(f_{b}<<F_{s}\right)$, we obtain

$$
\frac{\gamma_{1}}{2 \pi} \approx(1+G) f_{b} \text { and } \frac{\gamma_{2}}{2 \pi} \approx \frac{F_{s}}{\pi}-(1+3 G) f_{b} .
$$

These correspond to the two poles of the closed loop feedback system. We see that the closed loop bandwidth is roughly $(1+G)$ times the open loop bandwidth $f_{b}$.

Let us take an example of $f_{b}=30 \mathrm{~Hz}, F_{s}=4 \mathrm{kHz}$, and $G=3$. Then from Eqs. (5.6) and (5.14), the solutions are

$$
\mathrm{c}=42.4, \quad \gamma_{1}=0.228 \mathrm{~F}_{\mathrm{S}}, \quad \text { and } \quad \gamma_{2}=1.514 \mathrm{~F}_{\mathrm{S}} \text {, }
$$

and the eigenfrequencies are

$$
f_{1}=\frac{\gamma_{1}}{2 \pi}=145 \mathrm{~Hz} \quad \text { and } \quad f_{2}=\frac{\gamma_{2}}{2 \pi}=964 \mathrm{~Hz} .
$$

Both $f_{1}$ and $f_{2}$ are positive real, and therefore, the system is stable. The bandwidth has also been broadened by a factor of 5 from the open loop bandwidth of $30 \mathrm{~Hz}$.

\subsection{Digital Feedback with Multiple Filtering Elements}

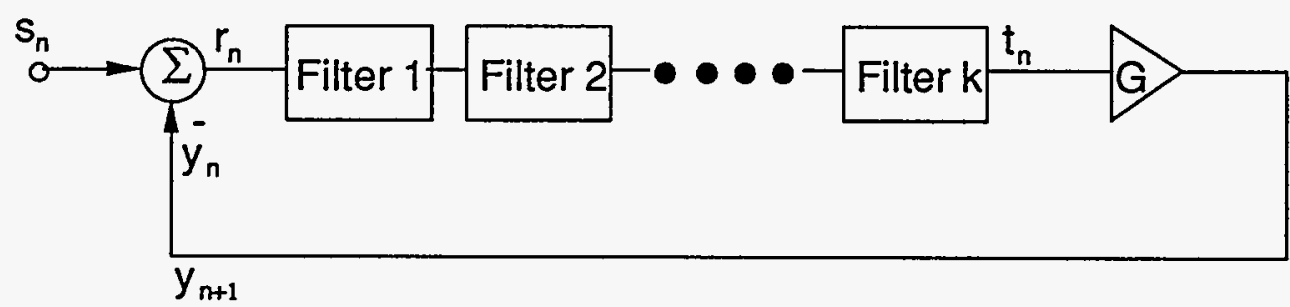

Fig. 5.3: Closed loop feedback with multiple filtering elements.

The analysis presented in the last section for a closed loop feedback system with one filtering element can be generalized to systems with multiple filtering elements connected in series as shown in Fig. 5.3. Including more filters in the system can degrade the overall performance of the system by introducing a large open loop phase shift. However, it is sometimes necessary to do so in order to prevent overshoot and oscillation when the open loop bandwidth is too large for a given sampling frequency and loop gain. For example, the beam position feedback system uses corrector magnets and beam position 
monitors (BPMs). When the bandwidth of the BPM is too large, it must be compensated by another low pass filter in the digital signal processing unit. Reducing the bandwidth of the BPM itself by integrating data for a longer time is not as good a solution for several reasons: 1) the number of turns required may be too large, 2) simple integration may result in oscillation due to undesirable large phase shift beyond the bandwidth, and 3) the DSP does 32-bit floating point operation and therefore is more accurate than the BPM processing unit.

The relation for the loop gain, the open loop bandwidth, and the sampling frequency of an optimally controlled closed loop feedback system will be derived in Section 5.4. In this section, we will replace analog components, such as the vacuum chamber, the magnet, and the analog reconstruction filter, with corresponding digital filters with firstorder poles, so that the system response may be put in the form of Eq. (5.13).

Let us take the case of three $(n=3)$ filters with filter coefficients $c_{1}, c_{2}$, and $c_{3}$, which are given by

$$
c_{i}=\cot \left(\frac{\pi f_{i}}{F_{s}}\right) . \quad(i=1,2,3)
$$

$f_{i}$ is the frequency of $3 \mathrm{~dB}$ attenuation of the $\mathrm{i}$-th filter. It can be shown that the output $y$ in the continuous domain satisfies the differential equation given by

$$
d_{4} y^{\prime \prime \prime \prime}+d_{3} y^{\prime \prime \prime}+d_{2} y^{\prime \prime}+d_{1} y^{\prime}+d_{0} y=d_{0} \frac{G}{1+G} s,
$$

where

$$
\begin{aligned}
& d_{4}=\left(1+c_{1}\right)\left(1+c_{2}\right)\left(1+c_{3}\right)+G, \\
& d_{3}=2\left(\left(1+c_{1}\right)\left(1+c_{2}\right)\left(1+c_{3}\right)-G\right), \\
& d_{2}=4\left(2+c_{1}+c_{2}+c_{3}+c_{1} c_{2}+c_{2} c_{3}+c_{3} c_{1}+2 G\right), \\
& d_{1}=8\left(1+c_{1}+c_{2}+c_{3}-G\right), \\
& d_{0}=16(1+G) .
\end{aligned}
$$

The secular equation for Eq. (5.20) is

$$
d_{4} \gamma^{4}-d_{3} \gamma^{3} F_{s}+d_{2} \gamma^{2} F_{s}^{2}-d_{1} \gamma F_{s}^{3}+d_{0} F_{s}^{4}=0
$$

With solutions $\gamma_{1}, \gamma_{2}, \gamma_{3}$ and $\gamma_{4}$ from Eq. (5.22), we have an expression similar to Eq. (5.13), 
(a)

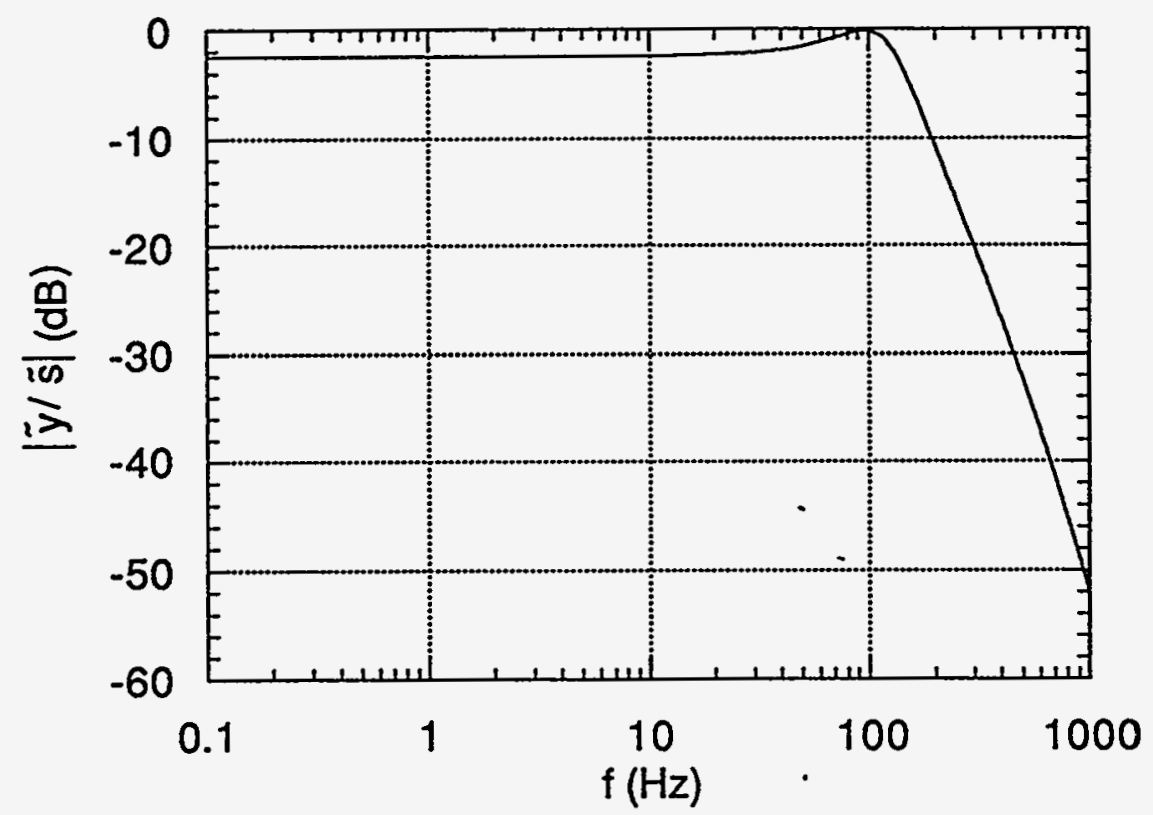

(b)

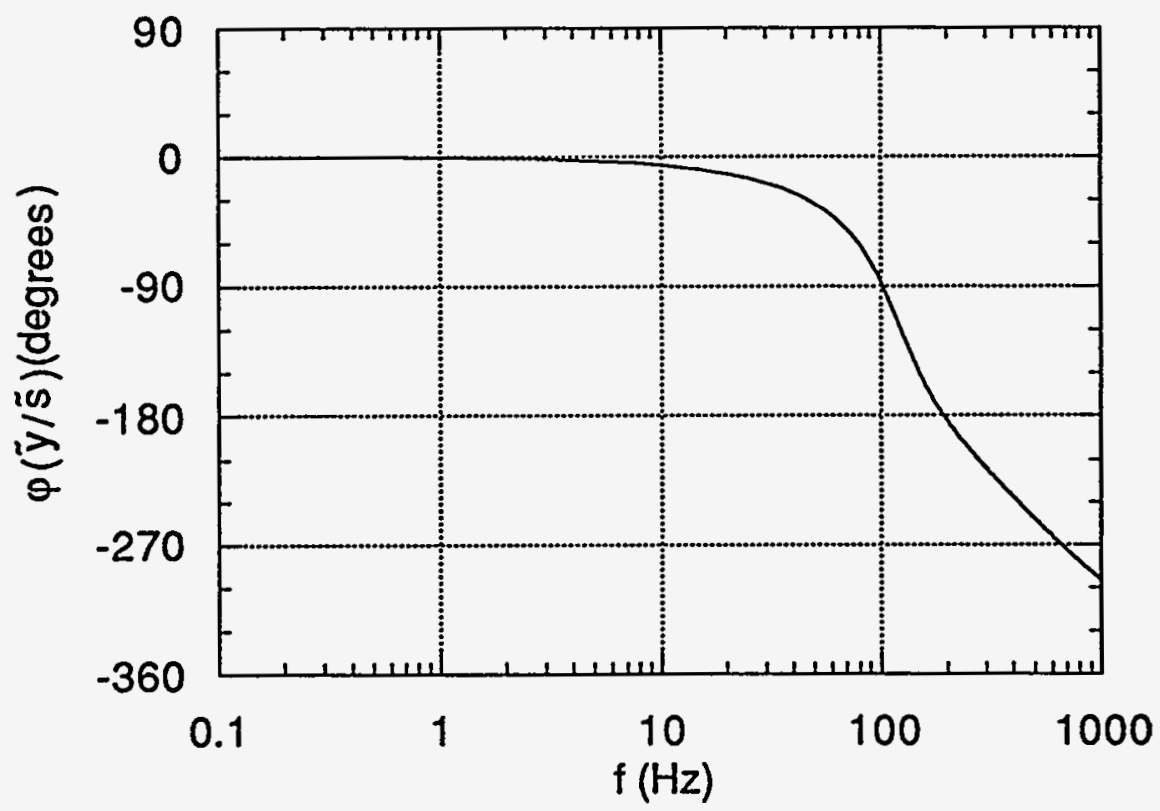

Fig. 5.4: Frequency response of the closed loop feedback system with parameters in Eq. (5.25), (a) magnitude and (b) phase. Note that there is a resonance at $\mathrm{f} \approx 100 \mathrm{~Hz}$. 


$$
\tilde{y}=\tilde{s} \frac{G}{1+G}\left(\frac{\gamma_{1}}{\gamma_{1}-i \omega}\right)\left(\frac{\gamma_{2}}{\gamma_{2}-i \omega}\right)\left(\frac{\gamma_{3}}{\gamma_{3}-i \omega}\right)\left(\frac{\gamma_{4}}{\gamma_{4}-i \omega}\right) \text {. }
$$

In Eq. (5.23), the overall system response resembles that of a filter with poles at $\omega$ $=\gamma_{j}(j=1,2,3,4)$. This result can be generalized to the case of $\mathrm{k}$ poles. A feedback system with $\mathrm{k}$ open loop poles, counting $\mathrm{m}$-th order poles as $\mathrm{m}$ poles, can be represented as a filter of $k+1$ poles in the complex plane. That is,

$$
\text { k open loop poles } \rightarrow \tilde{y}=\tilde{s} \frac{G}{1+G} \prod_{j=1}^{k+1}\left(\frac{\gamma_{j}}{\gamma_{j}-i \omega}\right) \text {, }
$$

where $\gamma_{j}$ 's are solutions of the corresponding $(n+1)$-th order polynomial obtained by performing transformations similar to Eq. (5.10).

Let us take an example of a 3-pole system with the following parameters:

$$
f_{1}=30 \mathrm{~Hz}, \quad f_{2}=100 \mathrm{~Hz}, f_{3}=200 \mathrm{~Hz}, \quad \text { and } G=3 \text {. }
$$

From Eqs. (5.21) and (5.22), we have, in units of $\mathrm{Hz}$,

$$
\frac{\gamma_{1}}{2 \pi}=48+109 \mathrm{i}, \quad \frac{\gamma_{2}}{2 \pi}=48-109 \mathrm{i}, \quad \frac{\gamma_{3}}{2 \pi}=426, \quad \text { and } \quad \frac{\gamma_{4}}{2 \pi}=749
$$

The real parts are all positive, and, therefore, the system is stable. The imaginary parts indicate frequency shift of the system response and resonances will appear in the system response near those frequencies. This is typical of closed loop feedback and can be readily recognized using Nyquist diagrams. Figure 5.4 shows the frequency response of the system with the parameters in Eq. (5.25).

\subsection{Determination of Sampling Frequency, Bandwidth, and Gain}

In the last two sections we analyzed digital feedback systems with one or multiple filtering elements in the closed loop. In this section we will use the results of Section 5.1 for systems with one filter to obtain the optimal parameters for the sampling frequency, bandwidth, and gain. We will use only one filter to make the system simpler to analyze and the eigenfrequencies easier to identify. The results will later be applied to measurements on and compensation for effect of the vacuum chamber eddy current for control of the corrector magnet field in the vacuum chamber. 
When the roots of Eq. (5.14) are the same $\left(\gamma_{1}=\gamma_{2}\right)$, the system is critically damped and provides the optimal control with the shortest settling time without overshoot. The open loop gain $G_{c}$ that corresponds to critical damping is, from Eq. (5.14),

$$
\mathrm{G}_{\mathrm{c}}=\frac{2}{3} \sqrt{3 \mathrm{c}^{2}+6 \mathrm{c}+4}-\mathrm{c}-\frac{5}{3} \approx 0.155 \mathrm{c}-0.5 \text {. }
$$

In the last step of Eq. (5.27), the expression in the square root was expanded assuming that $c$ is much larger than 1 . This assumption is verified immediately. The gain $G_{c}$ must be large for effective control, and therefore, c must also be large. Equation (5.27) is the necessary condition for the output to be critically damped at application of a step impulse input. When $G$ is larger than $G_{c}$, the output will be underdamped, causing oscillation. In the opposite case when $G$ is smaller than $G_{c}$, the output will be overdamped, resulting in longer settling time. From Eqs. (5.6) and (5.27), we have, when $f_{b} \ll F_{s}$ and $G \gg 1$,

$$
\frac{F_{s}}{G f_{b}} \approx 20 \text {. }
$$

Equation (5.28) is the basic relation for loop gain, open loop bandwidth, and sampling frequency of an optimally controlled feedback system with one bandlimiting filter connected in series with a constant open loop gain $\mathrm{G}$.

In the case of a more complex PID (proportional, integral, and derivative) control, we must also consider the effect of the integral and derivative control gains, $\mathrm{K}_{\mathrm{I}}$ and $\mathrm{K}_{\mathrm{D}}$. However, when $\mathrm{K}_{\mathrm{I}}$ is small $(<<1)$, the frequency range of concern for loop stability is primarily covered by the proportional control action, and therefore, Eq. (5.28) with $G$ replaced by $\mathrm{K}_{\mathrm{P}}$ remains valid.

\section{Measurement of the Vacuum Chamber Eddy Current Effect}

In this section, we will present the results of measurement of the effect of the vacuum chamber eddy current on the magnet field. The setup is the same as that shown in Fig. 2.1(b) in the open loop configuration (switch $S_{A}$ closed). The power supply was in the current-controlled mode, which has an internal closed loop of its own.

Figure 6.1 shows the schematic diagram for closed loop feedback with PID control for the magnetic field. There are two types of input: $s_{n}$ for set points and $w_{n}$ for external perturbation. In this measurement, only one of them was used at a time. When the $s_{n}$ input is used, $w_{n}$ is set to 0 , and vice versa. In this configuration, the spectral ratio of $y_{n}$ 


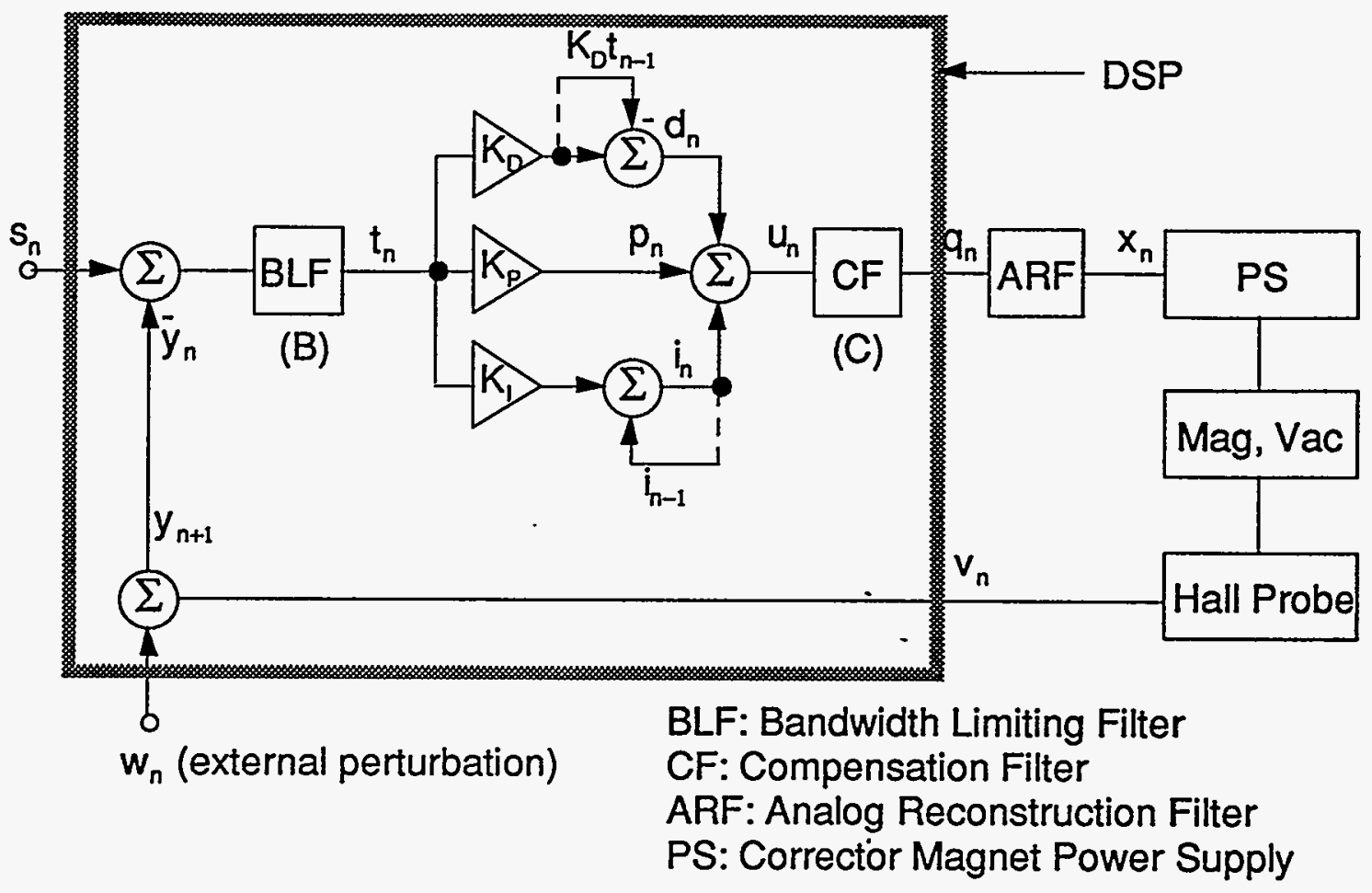

Fig. 6.1: Schematic diagram for the closed loop feedback with PID control.

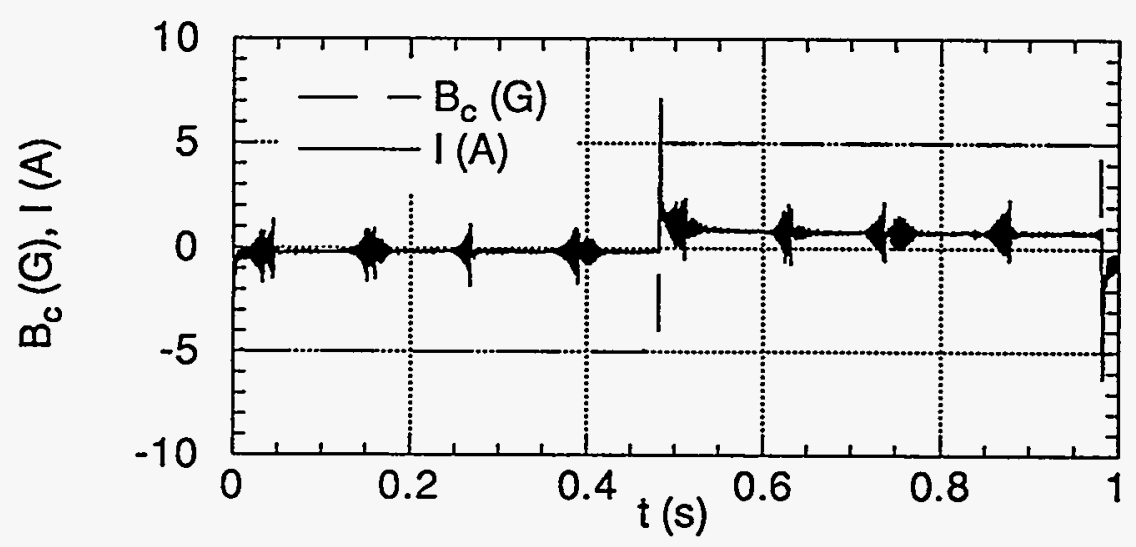

Fig. 6.2: Ringing in the magnet current with the feedback loop closed (solid line). The dotted line is the field control signal of $1 \mathrm{~Hz}$ square pulse. The ARF was turned off and the parameters used were: $F_{S}=2 \mathrm{kHz}, \mathrm{f}_{\mathrm{b}}=20 \mathrm{~Hz}, \mathrm{~K}_{\mathrm{P}}=3, \mathrm{~K}_{\mathrm{I}}=0.1$, and $\mathrm{K}_{\mathrm{D}}=1$. 
and $s_{n}$ gives the system transfer function of the closed loop feedback system and the spectral ratio of $y_{n}$ and $w_{n}$ gives its noise transfer function.

The analog reconstruction filter (ARF) is an analog low pass filter of $200 \mathrm{~Hz}$ bandwidth. It was inserted in front of the power supply control input in order to suppress the anomalous high frequency ringing in the magnet current, as shown in Fig. 6.2, when the feedback loop was closed. It was also intended to simulate the BPM, which will have finite bandwidth due to averaging over many turns. This ringing was observed when the DSP could not keep up with the sampling frequency and failed to operate synchronously with the $A D C$. It was not observed when the loop was open. The backlog in the DSP causes bursts of oscillation as is observed if the open loop bandwidth is not narrow enough to suppress them.

\subsection{Measurement Results and Design of Digital Compensation Filter}

Figure 6.3 shows the results of measurement on the amplitude ratios and relative phases of the current control signal $I_{C}$, the actual current on the magnet $I$, and the magnetic field $B$ in the vacuum chamber measured with a Hall probe in the frequency range of 0.1 $\mathrm{Hz}-1 \mathrm{kHz}$. This apparently wide range of frequency of measurement is necessary for the design of the digital compensation filter for the eddy current.

The effect of the eddy current in the vacuum chamber is shown in the rapid decrease of the field current ratio $(\mathrm{B} / \mathrm{I})$ with frequency. The phase delay of $35^{\circ}$ between the current control signal $I_{C}$ and the magnet current $I$ at $1 \mathrm{kHz}$ is due to the internal closed loop feedback for current control. The bandwidth of the power supply in the current-controlled mode is rated at $10 \mathrm{kHz}$ for $-3 \mathrm{~dB}$ attenuation.

The attenuation and phase shift of the field $B$ with respect to the current I has an adverse effect on the closed loop feedback by decreasing the magnet field efficiency and deteriorating the stability of the feedback loop. This can be partly remedied by inserting a digital compensation filter (CF in Fig. 6.1) in front of the power supply control input. The digital compensation filter is designed such that its input and the digitized signal from the gaussmeter have ratio close to unity within the frequency range of our interest. The measurement results of the field attenuation is normalized to dimensionless units and fitted to an expression as given by 6,7

$$
H(z)=C \prod_{k=1}^{K} \frac{1+f_{k} z^{-1}+g_{k} z^{-2}}{1+c_{k} z^{-1}+d_{k} z^{-2}} .
$$


(a)

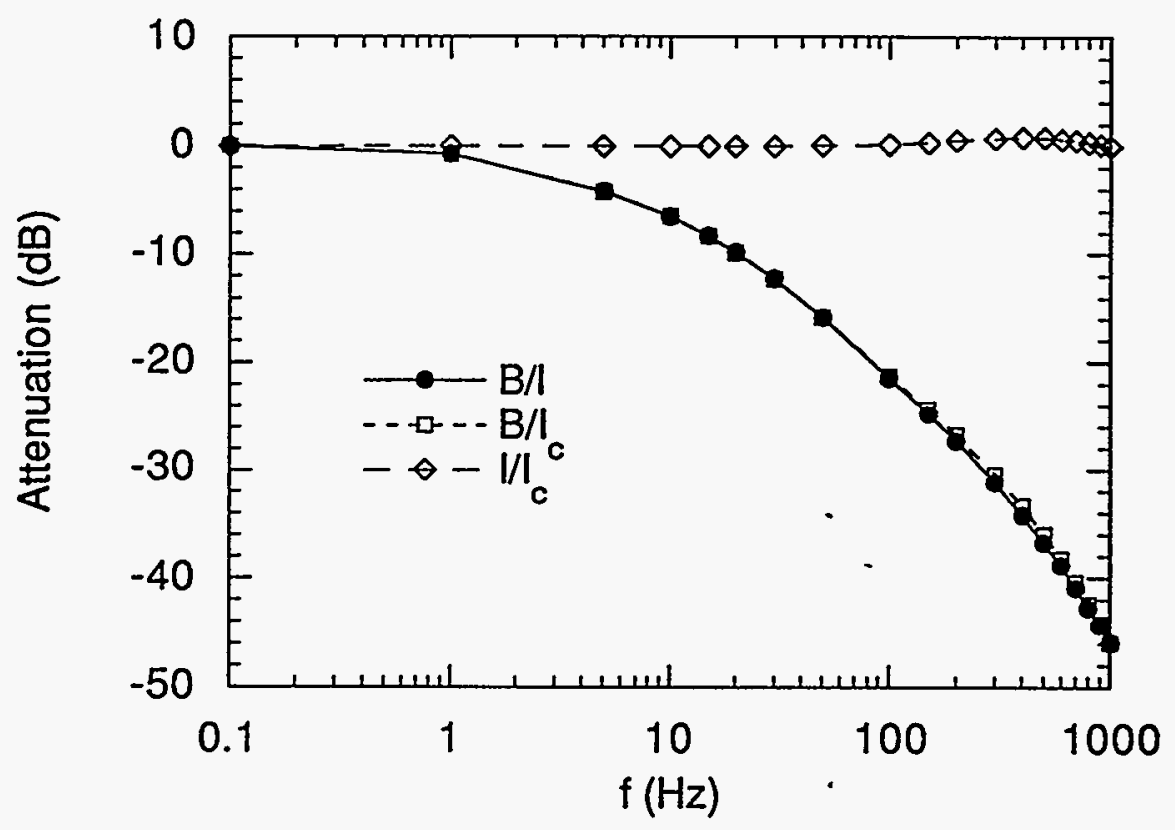

(b)

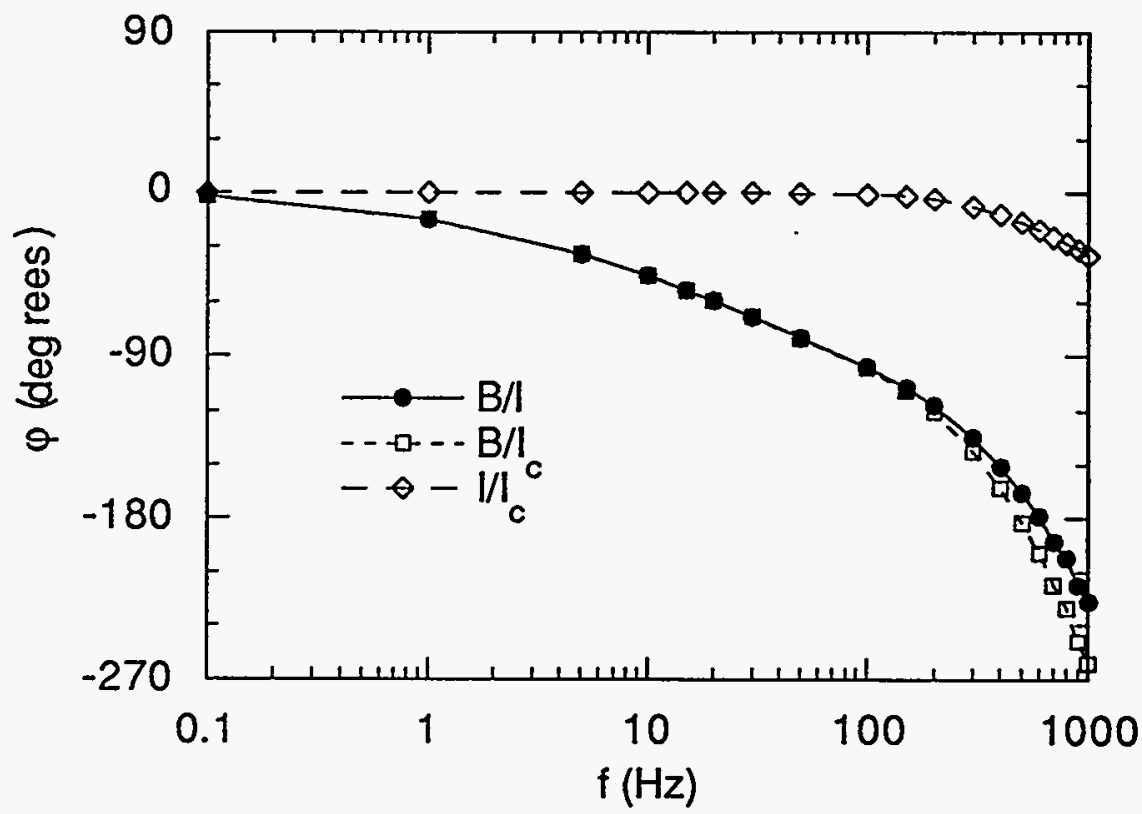

Fig. 6.3: Results of the open loop measurements on (a) the amplitude ratios and (b) the relative phases of current control signal $\mathrm{I}_{\mathcal{C}}$, magnet current $\mathrm{I}$, and the magnetic field $\mathrm{B}$ in the vacuum chamber. 
Here, $z=e^{-i \lambda}$ and $\lambda$ is the digital frequency given by

$$
\lambda=2 \tan ^{-1}\left(\frac{\pi f}{F_{s}}\right) \approx \pi \frac{2 f}{F_{s}} \text { when } \mathrm{f} \ll F_{s} .
$$

The transfer function $\mathrm{H}(\mathrm{z})$ relates the $\mathrm{Z}$-transforms $\mathrm{V}(\mathrm{z})$ and $\mathrm{X}(\mathrm{z})$ of the sequences $\left\{\mathrm{x}_{\mathrm{n}}\right\}$ and $\left\{v_{n}\right\}$ shown in Fig. 6.1 through

$$
\mathrm{V}(\mathrm{z})=\mathrm{H}(\mathrm{z}) \mathrm{X}(\mathrm{z}) \text {. }
$$

For more discussion on the $\mathrm{Z}$-transform of discreet sequences, readers are referred to Refs. 6 and 7. The transfer function corresponding to the $C F$ is just the inverse of $H(z)$. Let $U(z)$ and $Q(z)$ be the $Z$-transforms of the sequences $\left\{u_{n}\right\}$ and $\left\{q_{n}\right\}$, then we have

$$
Q(z)=\frac{1}{H(z)} U(z) \text {. }
$$

Putting

$$
\mathrm{H}(\mathrm{z})=\frac{\sum_{\mathrm{k}=0}^{\mathrm{M}} \mathrm{a}_{\mathrm{k}} \mathrm{z}^{-\mathrm{k}}}{1+\sum_{\mathrm{k}=1}^{\mathrm{L}} \mathrm{b}_{\mathrm{k}} \mathrm{z}^{-\mathrm{k}}}
$$

we can write the inverse of $\mathrm{H}(\mathrm{z})$ as

$$
\frac{1}{H(z)}=\frac{1}{a_{0}} \frac{\sum_{k=0}^{L} b_{k} z^{-k}}{1+\sum_{k=1}^{M} \frac{a_{k}}{a_{0}} z^{-k}} \quad\left(b_{0}=1\right)
$$

and we have

$$
\mathrm{q}_{\mathrm{n}}=\frac{1}{\mathrm{a}_{0}}\left(\mathrm{u}_{\mathrm{n}}+\sum_{\mathrm{k}=1}^{\mathrm{L}} \mathrm{b}_{\mathrm{k}} \mathrm{u}_{\mathrm{n}-\mathrm{k}}-\sum_{\mathrm{k}=1}^{\mathrm{M}} \mathrm{a}_{\mathrm{k}} \mathrm{q}_{\mathrm{n}-\mathrm{k}}\right) .
$$

Using the measurement results shown in Fig. 6.3(a) and with $\mathrm{K}=2$ and $F_{S}=4 \mathrm{kHz}$, the best fit gives 


$$
\begin{gathered}
C=0.0173025 \\
c_{1}=1.94223, d_{1}=0.94284, f_{1}=-0.90665, g_{1}=-0.08920, \\
c_{2}=-1.21537, d_{2}=0.21730, f_{2}=-0.69730, g_{2}=-0.26649
\end{gathered}
$$

The Hall probe sensitivity of $10 \mathrm{G} / \mathrm{V}$ and the power supply control sensitivity of $2 \mathrm{~A} / \mathrm{V}$ were used. From Eqs. (6.1), (6.5), (6.7) and (6.8), we obtain

$$
\begin{aligned}
q_{n}= & 57.8\left(u_{n}-3.1576 u_{n-1}+3.5207 u_{n-2}-1.5679 u_{n-3}+0.2049 u_{n-4}\right)+ \\
& 1.6040 q_{n-1}-0.2765 q_{n-2}-0.3038 q_{n-3}-0.0238 q_{n-4} .
\end{aligned}
$$

The sequence $\left\{u_{n}\right\}$ is in units of dimensionless computer counts converted from voltage. From Eq. (6.9), the next output of the compensation filter is calculated using the current input, 4 previous inputs, and 4 previous outputs. Since no future samples from either the input or output are needed to calculate the current output, the filter is physically realizable or causal.

\subsection{Performance of the Closed Loop Feedback}

Figures 6.4(a) and 6.4(b) show the results of measurements on the closed loop feedback for the corrector magnet field in the vacuum chamber. A bandlimiting filter (BLF) of $30 \mathrm{~Hz}$ was used for these measurements. The eddy current compensation filter was turned on and off during measurements for comparison. For the open loop measurements, $\mathrm{B}_{\mathrm{c}}$ is the control signal at either the input of the $\mathrm{CF}$ ( $\mathrm{u}_{\mathrm{n}}$, with $\mathrm{CF}$ ) or the input of the PS ( $\mathrm{q}_{\mathrm{n}}$, without $\mathrm{CF}$ ) in Fig. 6.1. The ARF of $200 \mathrm{~Hz}$ bandwidth in front of the power supply was turned off. For the closed loop measurements, $\mathrm{B}_{\mathrm{c}}$ is the control signal at the input of the DSP $\left(\mathrm{s}_{\mathrm{n}}\right)$ in Fig. 6.1. The CF was turned on (with CF) or off (without CF) and the ARF in front of the power supply was turned on. These results primarily compare the system performance with and without the $\mathrm{CF}$.

Compensation for the eddy current effect by the CF is almost perfect in restoring the amplitude. Still, there is significant phase delay remaining $\left(-79^{\circ}\right.$ at $\left.200 \mathrm{~Hz}\right)$, because the transfer function $\mathrm{H}(\mathrm{z})$ in Eq. (6.1) does not simultaneously model the eddy current effect perfectly in both amplitude and phase. The coefficients in Eq. (6.8) were obtained in such a manner that only the amplitude data fit $\mathrm{lH}(\mathrm{z}) \mathrm{l}$ as closely as possible with $\mathrm{K}=2$. 
(a)

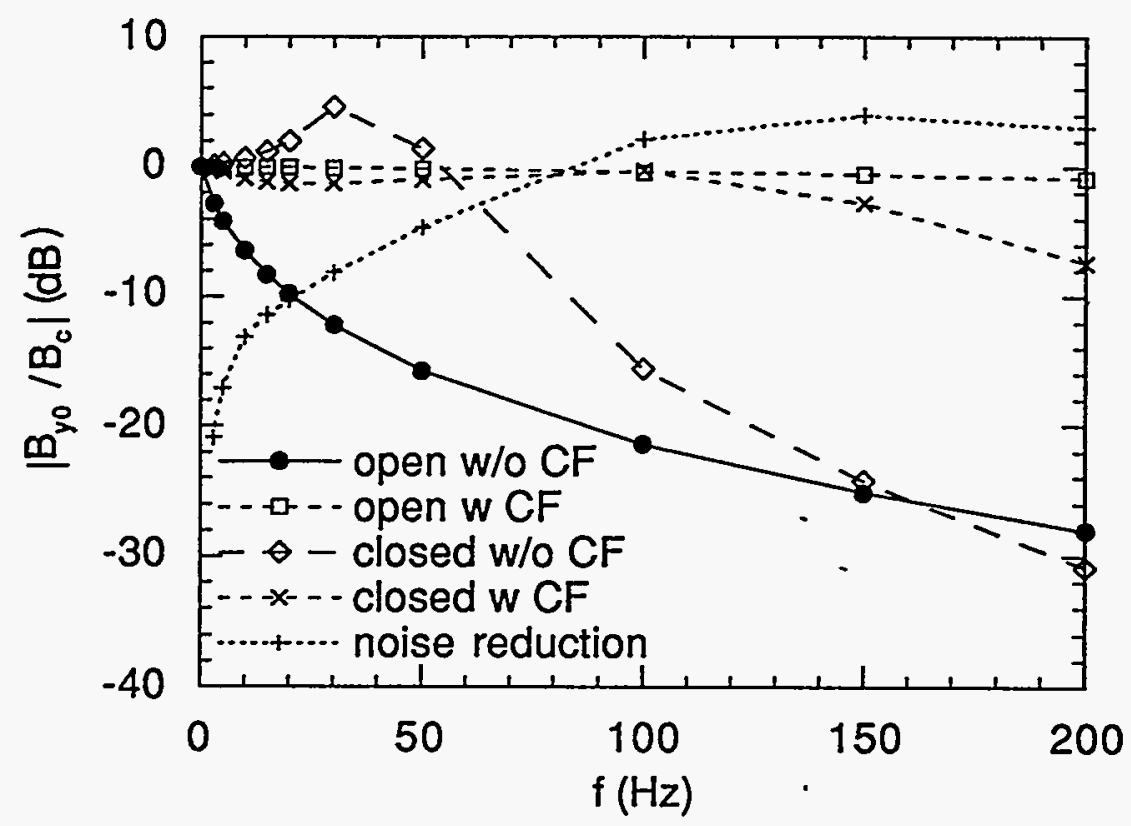

(b)

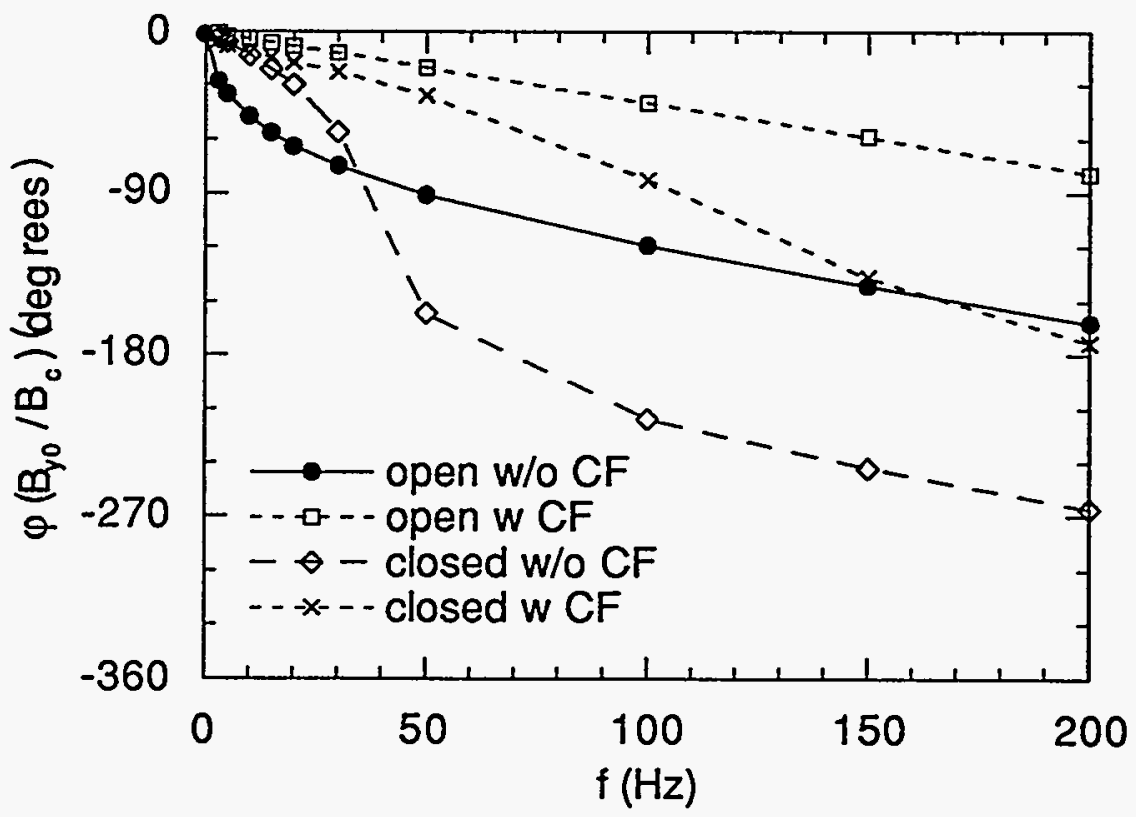

Fig. 6.4: Results of measurement on the closed loop feedback for corrector magnet field: (a) amplitude attenuation and (b) phase shift. For closed loop measurements, an analog reconstruction filter of $200 \mathrm{~Hz}$ bandwidth was inserted in front of the power supply to suppress ringing. The parameters used were: $F_{s}=4 \mathrm{kHz}, \mathrm{f}_{\mathrm{b}}=30 \mathrm{~Hz}, \mathrm{~K}_{\mathrm{P}}=3, \mathrm{~K}_{\mathrm{I}}=0.05$, and $\mathrm{K}_{\mathrm{D}}=0.5$. 
Figure 6.5 shows time domain measurements of the magnetic field $B$ inside the vacuum chamber and the magnet current $I$ in response to the input square pulses of $15 \mathrm{~Hz}$ with the CF turned off. Figure 6.6 shows similar measurements with the CF turned on for comparison. The results demonstrate the clear advantage of canceling the effect of the eddy current. Without the CF, as shown in Fig. 6.5(b), the magnetic field exhibits strong oscillation. This can be explained from the analysis of Section 5.2, considering the vacuum chamber as a low-pass filter to the $\mathrm{AC}$ magnetic field with several poles on the imaginary axis of the complex frequency space. Closing the feedback loop adds one more pole to these and rearranges them. If some of these rearranged poles have real parts, especially those with the smallest imaginary parts, then the overall system response could amplify the low frequency components and oscillation results. This is also shown in Fig. 6.4(a), where the amplitude ratio $1 \mathrm{~B}_{\mathrm{y}} / \mathrm{B}_{\mathrm{c}} /$ measured on the feedback loop without the $\mathrm{CF}$ is larger than unity below $50 \mathrm{~Hz}$, with a peak at around $30 \mathrm{~Hz}$, and decreases sharply. In comparison, the feedback loop with the CF shows a much cleaner response.

From this consideration, one might say that the feedback system response without the $\mathrm{CF}$ could be improved by broadening the bandwidth of the BLF, since locating the pole farther away from the origin will move the peak to a higher frequency. This is not necessarily true. Consider the single-pole low-pass filter transfer function

$$
F(\omega)=\frac{\gamma}{\gamma-i \omega}=\frac{\gamma_{r}+i \gamma_{i}}{\gamma_{r}+i\left(\gamma_{i}-\omega\right)}
$$

At resonance $\left(\omega=\gamma_{i}\right)$, we have

$$
\mathbb{F}(\omega) I=\sqrt{1+Q^{2}} . \quad\left(\mathrm{Q}=\left|\frac{\gamma_{\mathrm{i}}}{\gamma_{\mathrm{r}}}\right|\right)
$$

Equation (6.11) shows that $|F(\omega)|$ will actually get larger, and therefore worse, if the Qfactor increases.

\section{Summary}

In this work, the magnet impedance and the attenuation and phase shift of the magnet field with respect to the magnet current due to the vacuum chamber eddy current were measured as functions of frequency in the range $\mathrm{DC}$ to $200 \mathrm{~Hz}$. The magnet was the storage ring sextupole magnet with vertical correction winding, and a 4 foot-long piece of the APS storage ring vacuum chamber was inserted in the magnet bore. 
(a)

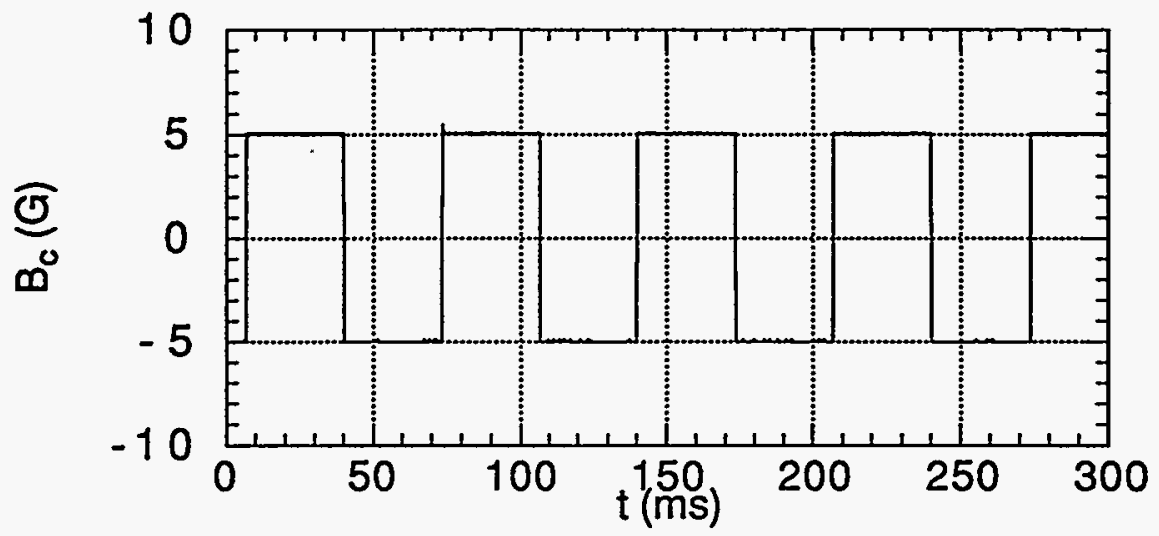

(b)

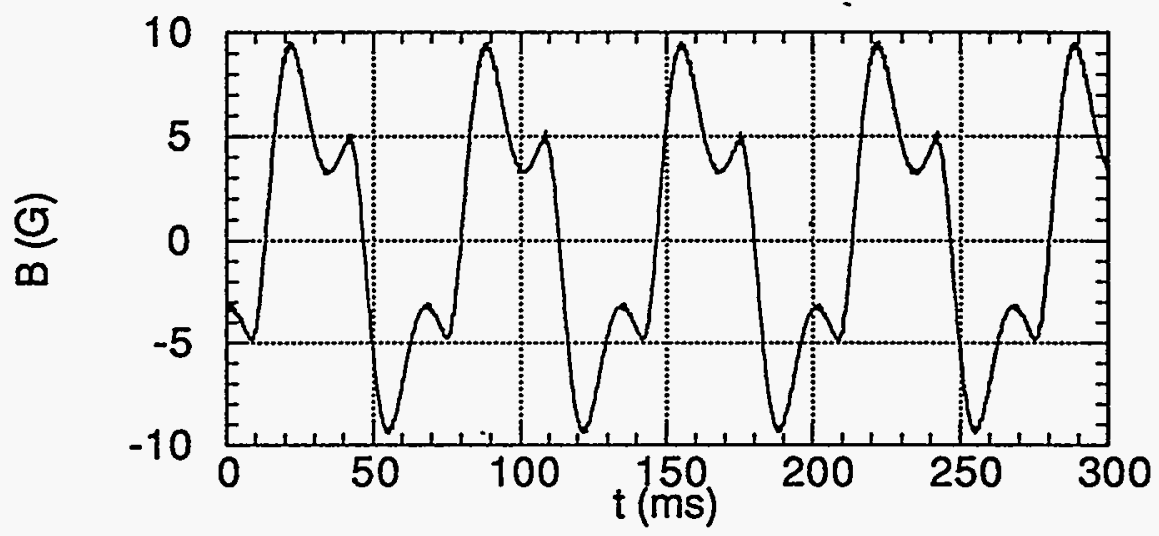

(c)

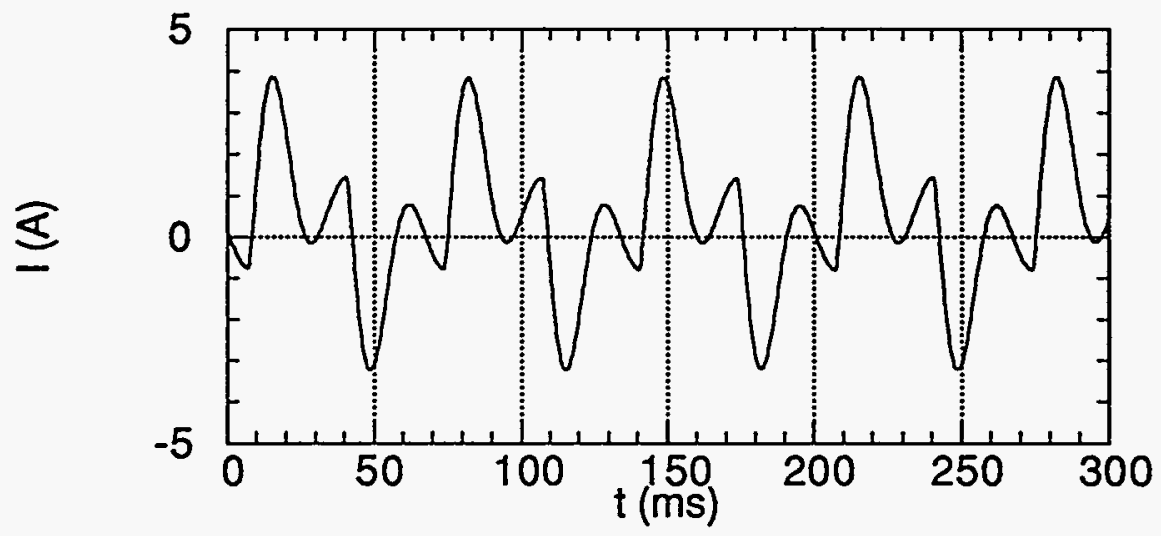

Fig. 6.5: Feedback system response in the time domain without eddy current compensation: (a) magnetic field control signal $\mathrm{B}_{\mathrm{c}}\left(\mathrm{s}_{\mathrm{n}}, 15 \mathrm{~Hz}\right.$ square wave), (b) magnetic field in the vacuum chamber $\left(\mathrm{y}_{n}\right)$, and (c) magnet current $I$. The parameters used were: $F_{s}$ $=4 \mathrm{kHz}, \mathrm{f}_{\mathrm{b}}=30 \mathrm{~Hz}, \mathrm{~K}_{\mathrm{P}}=3, \mathrm{~K}_{\mathrm{I}}=0.05$, and $\mathrm{K}_{\mathrm{D}}=0.5$. 
(a)

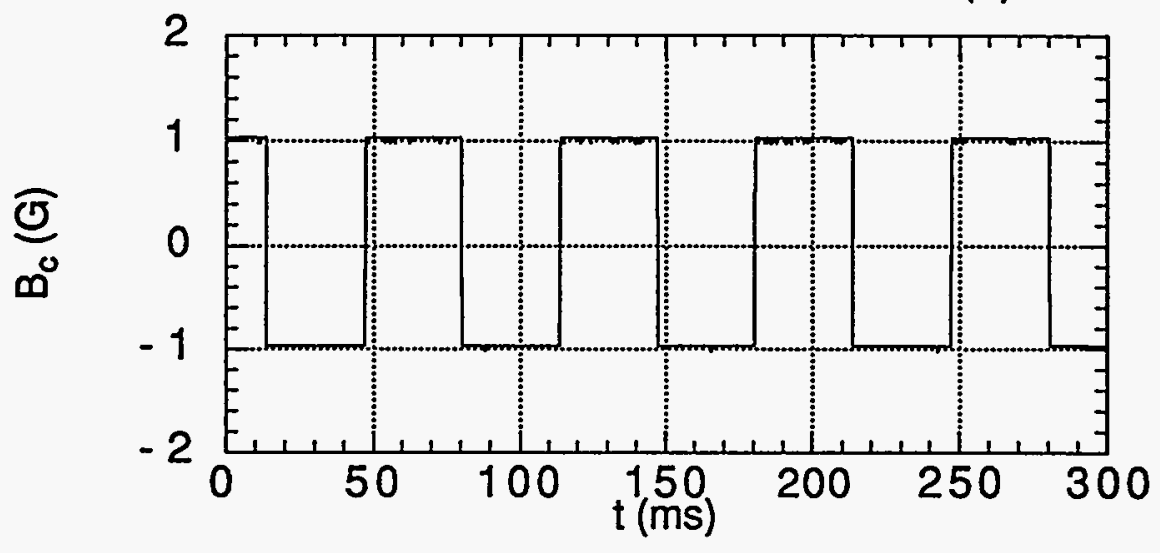

(b)

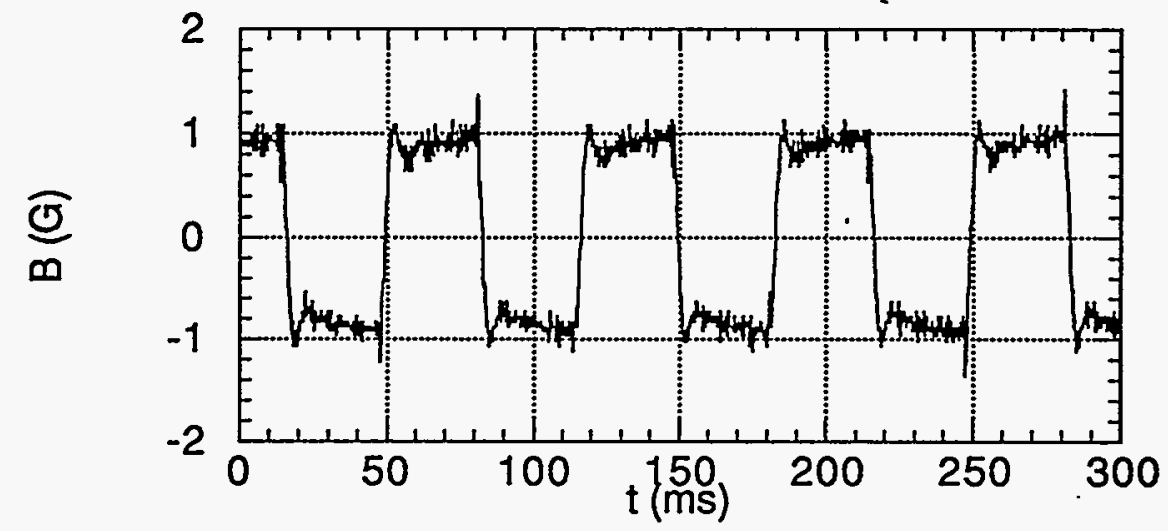

(c)

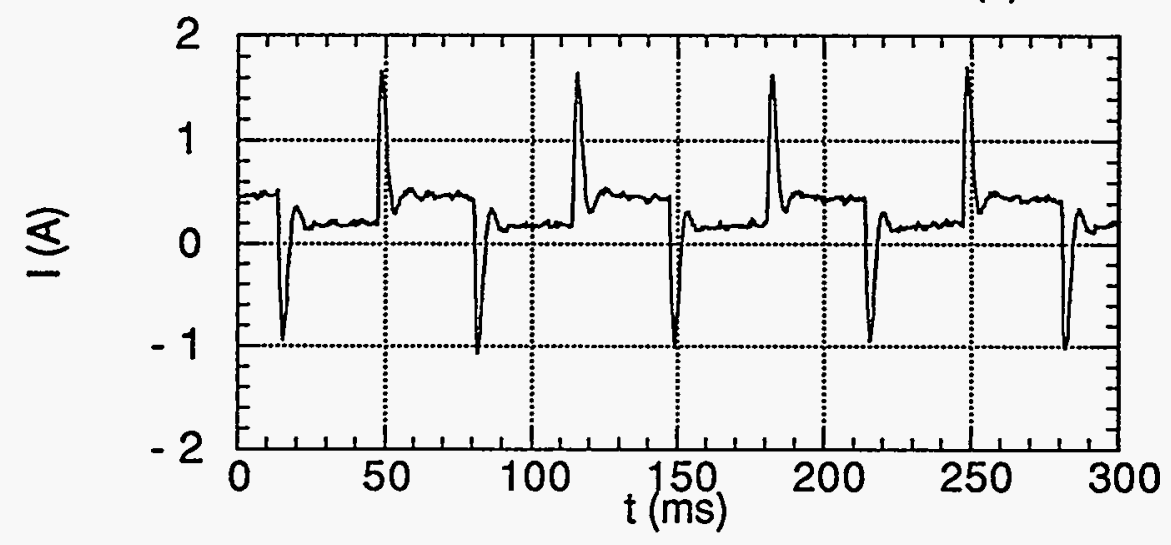

Fig. 6.6: Feedback system response in the time domain with eddy current compensation: (a) magnetic field control signal $B_{c}\left(s_{n}, 15 \mathrm{~Hz}\right.$ square wave), (b) magnetic field in the vacuum chamber $\left(y_{n}\right)$, and (c) magnet current $I$. The parameters used were: $F_{s}=4 \mathrm{kHz}, f_{b}$ $=30 \mathrm{~Hz}, \mathrm{~K}_{\mathrm{P}}=3, \mathrm{~K}_{\mathrm{I}}=0.05$, and $\mathrm{K}_{\mathrm{D}}=0.5$. 
The results show significant attenuation and phase shift of the magnet field $(-3.2 \mathrm{~dB}$ and $-49^{\circ}$ for $B_{x}$, and $-10.1 \mathrm{~dB}$ and $-60^{\circ}$ for $B_{y}$ at $20 \mathrm{~Hz}$ ) in the vacuum chamber. Large changes in magnet resistance and inductance were also observed. Spatially resolved measurements of $\mathrm{B}_{\mathrm{y}}$ at the midplane revealed strong quadrupole and sextupole components in the low frequency range below $50 \mathrm{~Hz}$, which could potentially degrade global beam stability due to local bump closure error. This problem has yet to be identified in a manner rigorous and quantitative enough to be properly resolved.

Conditions for optimal control were obtained through development of a theory of digital feedback. The results were successfully applied to closed loop control of the magnetic field in the vacuum chamber in combination with the eddy current compensation filter, using digital signal processing (DSP) and a proportional, integral, and derivative (PID) control algorithm. These two, together with the singular value decomposition (SVD) technique for matrix inversion, 6,11 will be the basis for the global and local beam position feedback in the APS storage ring. 


\section{Acknowledgement}

The author would like to thank G. Decker and A. Lumpkin for their support and interest in this work. Thanks go to S. Kim, his magnet measurement crew, and L. Erwin for their help in preparing the measurement setup.

\section{References}

1. Y. Chung, "Compensation for the Eddy Current Effect in the APS Storage Ring Vacuum Chamber," LS Note 148, Argonne National Lab, 1990.

2. Y. Chung, J. Bridges, L. Emery and G. Decker, "Open Loop Compensation for the Eddy Current Effect in the APS Storage Ring Vacuum Chamber," Proceedings of IEEE Particle Accelerator Conference, San Francisco, 1991.

3 Y. Chung and K. Kim, unpublished.

4 Fermilab Electron Cooling Experiment, Design Report, FNAL (1978).

5. Y. Chung and J. Galayda, "Effect of Eddy Current in the Laminations on the Magnet Field," LS Note 200, ANL, 1992.

6. Y. Chung, L. Emery, and K. Kirchman, "Digital Signal Processing for Beam Position Feedback," LS Note 202, ANL, 1992.

7. A. Peled and B. Liu, Digital Signal Processing, John Wiley \& Sons, 1976.

8. L. Turner, private communication.

9. W. Press et al., Numerical Recipes in C, Cambridge University Press, p. 528, 1989.

10. L. Emery, private communication.

11. W. Press et al., Numerical Recipes in C, Cambridge University Press, p. 60, 1989. 